\title{
Das angebliche Werk des Olynthiers Kallisthenes über Alexander den Grossen.
}

Die Nachrichten über den Menschen und den Schriftsteller Kallisthenes enthalten einen Widerspruch, dem merkwürdigerweise die Neueren ebensowenig Bedeutung beigelegt haben wie die Alten. Derselbe Mann soll durch seine freiheitliche Gesinnung sein Leben verwirkt und gleichwohl Alexander in einem Buche zu den Göttern erhoben haben.

Ehe wir diesen Widerspruch zu erklären versuchen, werden wir gut daran tun, die Ueberlieferung zu prüfen.

So sicher der Tod des Kallisthenes in Heerlager Alexanders bezeugt ist, so gehen doch schon über die Art seines Todes die Angaben 2weier unmittelbarer Zeugen des Ereignisses auseinander. Nach Ptolemaeus wurde er als Anstifter des Hermolaos gefoltert und gehenkt, nach Aristobulos starb er, in Fesseln mit dem Heere mitgeführt, an einer Krankheit ${ }^{1}$.

Man würde dem Zeugnis des Ptolemaeus unbedingten Glauben schenken, weil er der erste war, der von der Verschwörung des Hermolaos Kunde erhielt und dem König Mitteilung davon machte, wenn wir nicht dieses eben durch Aristobulos wübten, der sein Zeugnis bestritt 2).

Während aber Ptolemaeus und Aristobulos darin einig waren, dabs Kallisthenes von den Verschworenen als Urheber der Verschwörung genannt war ${ }^{3}$ ), versichert Plutarch das Gegenteil, indem er sich auf das Zeugnis des Königs beruft, der sofort an Krateros, Attalos und Alketas geschrieben habe, die

1) Arrian IV 14, 3. 2) 13,7.

Philologue LXXIV (N. F. XXVIII), 1.

s) 14,1 . 
Knaben hätten angegeben, dafs sie keinen Mitwisser hätten. Erst später habe er in einem Briefe an Antipater auch den Kallisthenes beschuldigt und gesagt, die Knaben seien von den Makedonen gesteinigt worden, den Sophisten aber werde er selbst bestrafen ebenso wie die, welche ihn ausgeschickt hätten und seine Widersacher in ihre Städte aufnähmen ${ }^{4}$ ).

Diese dritte Version geht offenbar auf einen andern zeitgenössischen Geschichtsschreiber Alexanders zurück, den Kammerherrn des Königs, Chares von Mitylene. Plutarch bezieht nämlich die Drohung des Königs auf Aristoteles, mit der Begründung, daf Kallisthenes bei diesem als Sohn seiner Kusine erzogen worden sei. Allein in Wahrheit ist dies offenbar gar keine Begründung, sondern Plutarch erwähnt dies nur, weil es ihm schon feststand, daß sich die Drohung auf Aristoteles bezog. Er muf also die Auslegung des Briefes von einem andern entlehnt haben, dem er ohne Zweifel auch die Kenntnis des Briefes selbst verdankt. Als solcher ergibt sich Chares, den er am Ende seines Berichtes gegen Ptolemaeus und Aristobulos als Gewährsmann dafür anführt, daß̇ Kallisthenes nach seiner Verhaftung sieben Monate in Gewahrsam gehalten worden sei, um vor dem Synhedrion mit Aristoteles konfrontiert zu werden, während der Kämpfe Alexanders mit den Mallern aber an der Phthiriase gestorben sei. Auf Chares wird auch wohl die Notiz bei Strabo XI p. 517 zurückgehen, daf Kallisthenes in der baktrischen Stadt Kariatai verhaftet worden sei.

Plutarch nennt den Chares aber nicht nur am Ende dieser Darstellung von dem Prozef des Kallisthenes, sondern auch am Anfang.

Bereits vor Entdeckung der Verschwörung des Hermolaos sei eine Entfremdung zwischen Alexander und Kallisthenes eingetreten, da dieser bei einem Gastmahl, durch das der König die Proskynesis einführen wollte, sie ihm als einziger nicht geleistet habe. Fast gleichlautend erzählt Arrian IV 12, 3-5 den Vorgang, ohne aber seinen Gewährsmann zu nennen. Er läbt aber diese Version auf eine andere Darstellung fol-

4) Alexander c. 55 . 
gen, deren Grundzüge, trotz bedeutender Differenzen und rhetorischer Ausschmückung, auch bei Curtius VIII 5, 7-24 zu erkennen sind. Hiernach habe, auch bei einem Gelage, nach vorheriger Verabredung der Sophist Anaxarchos eine Rede gehalten, man müsse Alexander schon bei Lebzeiten göttliche Ehren erweisen. Als er dann die Proskynesis habe beginnen wollen, habe Kallisthenes eine lange Rede in dem entgegengesetzten Sinne gehalten und die Proskynesis als eine verwerfliche Sitte bezeichnet.

Bei Arrian und Curtius folgt dann die Erzählung von der Verschwörung des Hermolaos, von der Plutarch nur die Folge berührt, die sie für Kallisthenes hatte. Für diese Erzählung gibt Arrian ausdrücklich Aristobulos als seinen Gewährsmann an. Nachdem er sie mit der Bemerkung geschlossen hat, daß wie Aristobulos so auch Ptolemaeus bezeugten, daß die Knaben den Kallisthenes der Anstiftung zu ihrem Unternehmen bezichtigt hätten, schließst er ganz kurz wieder eine abweichende Version an, die sich ebenso auf das engste mit Plutarch berührt ${ }^{5}$ ). Nach dieser sei kein Geständnis von den Knaben gegen Kallisthenes abgelegt, sondern die von anderer Seite gegen ihn erhobenen Beschuldigungen hätten infolge des bei Alexander bereits bestehenden Hasses - Plutarch hat dafür den milderen Ausdruck Entfremdung - leicht Glauben gefunden. Bei Plutarch wird diese Entfremdung aus der unmittelbar vorher nach Chares erzählten Unterlassung der Proskynesis abgeleitet. Es kann daher nicht bezweifelt werden, daßs auch dieses Mittelstück der Erzählung aus Chares stammt, obwohl er nicht ausdrücklich genannt ist. Auch Arrian meint, wie aus IV 12, 7 hervorgeht, daß der $\mathrm{HaE}$ Alexanders aus dem von ihm bei der Einführung der Proskynesis bewiesenen Freimut entstanden sei.

Chares hat also, ohne den Kallisthenes geradezu für unschuldig zu erklären, doch bis zu einem gewissen Grade für ihn Partei genommen, wahrscheinlich mit einer beabsichtigten Spitze, wenn nicht gegen Aristobulos, der eher von ihm die Feststellung übernommen haben möchte, daß Kallisthenes an einer Krankheit gestorben sei, so doch gegen Ptolemaeus.

5.) Arrian IV 14, 1 = Plut. $\Delta$ l. c. 55 Anf. 
Weder Ptolemaeus noch Aristobulos scheinen von dem Verhalten des Kallisthenes gegenüber den Versuchen Alexanders, die Proskynesis den Makedonen und Griechen aufzunötigen, gehandelt zu haben. Jedenfalls hat Arrian den ausführlichen Bericht darüber IV 10,5-12, 2 keinem ron beiden nacherzählt, das erkennt man schon an der Art, wie er ihn einführt ${ }^{6}$ ). Dieser ist gewiß stark aufgeputzt und macht durchaus einen weniger zuverlässigen Eindruck als der des Chares. Aber auch die Erzählung des Chares verleugnet nicht einen gewissen anekdotenhaften Charakter.

Es muß̧ aber doch auch Aristobulos mancherlei über den Charakter und das Benehmen des Kallisthenes berichtet haben, wie ein zufällig bei Athenaeus aufbewahrtes Geschichtchen beweist, für welches von ihm außer Lynkeus ron Samos und Chares auch Aristobulos als Gewährsmann angeführt wird ${ }^{7}$ ). Als der Becher mit ungemischtem Wein bei einem Gastmahl Alexanders an ihn gekommen'sei, habe er ihn zurückgewiesen, mit der Bemerkung, er benötige es nicht, des Asklepios zu benötigen, indem er auf Alexander trinke ${ }^{8}$ ). Aristoteles soll, wie Hermippos erzählte, als ihm der Vorleser des Kallisthenes von seiner Rede berichtete, in der er in Gegenwart Alexanders die Erfolge Philipps in einer kränkended Weise herabsetzte, geurteilt haben, Kallisthenes sei wohl redegewaltig gewesen, habe aber keine Einsicht gehabt ${ }^{9}$ ), (der wie es schärfer pointiert bei Iohannes Lydus ${ }^{10}$ ) heiß̧t, er jabe die höhere Einsicht besessen, aber die menschliche veroren ${ }^{11}$ ).

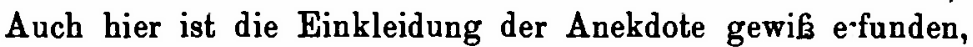
aber doch muk die darin enthaltene Auffassung weiter verbreitet gewesen sein. Es berührt sich damit das Urteil Ar-

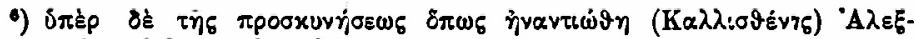

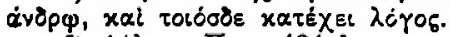

i) Athen. $\bar{X}$ p. $434 \mathrm{~d}$.

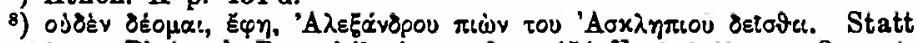

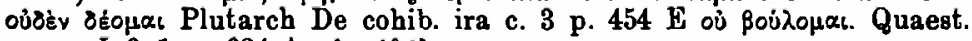

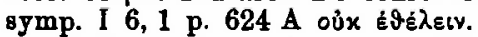

) Plut. Al. c. $54 . \quad{ }^{10}$ ) IV 77 p. 131,8 ed. Wuensch.

11) Aus der Erzählung bei Hermippos ist die Aneklote bei Laertius $\nabla 5$ entstanden. In denselben Kreig gèürt auch die Ge. schichte bei Valerius Maximus VII 2, 11, lauter Geschichen post eventum. 
rians ${ }^{12}$ ), nur dak es noch wesentlich schärfer ist. Kallisthenes sei ron einer allzugroßen Einfalt und einem unzeitigen Freimut gewesen. Ein ander Mal nennt er ihn geradezu etwas bäurisch ${ }^{13}$ ). Diese Urteile sind schwerlich ganz selbständig, sondern Arrian wahrscheinlich durch Aristobulos übermittelt. Verwandt damit, aber gewib aus anderer Quelle, ist die Charakteristik, die Plutarch Alex. c. 53 von Kallisthenes gibt. Er habe die Einladungen meistens abgelehnt, wenn er aber dabei gewesen sei, so habe er durch sein mürrisches und schweigsames Wesen seine Miß̧billigung gezeigt. Aeußerungen, die ihm zugeschrieben wurden, wie die, dak er Philotas auf die Frage, wer wohl von den Athenern am meisten geehrt worden sei, geantwortet habe: Harmodios und Aristogeiton ${ }^{14}$ ), oder daf er auf die Frage des Hermolaos, wie man am berühmtesten würde, versetzt habe: wenn man den Berühmtesten töte ${ }^{15}$ ), waren natürlich unverbürgt, aber alt. Die letztere steht in dem Kapitel bei Plutarch, das auf Chares zurückgeht, und wird von ihm als Verleumdung bezeichnet. Die Gegenüberstellung des servilen Anaxarchos und des sittenstrengen Kallisthenes bei Plutarch ${ }^{16}$ ) bringt elnen gewollten Kontrast zum Ausdruck, die gegensätzlichen langen Reden beider bei Arrian ${ }^{17}$ ) und Curtius ${ }^{18}$ ), bei dem an Stelle des Abderiten Anaxarchos der Sicilier Kleo getreten ist, sind auf rhetorische Wirkung berechnet; aber in beiden Fällen beruht doch die Charakteristik des Kallisthenes auf einer überlieferten, fest ausgeprägten Vorstellung. Theophrast beklagte in der Schrift

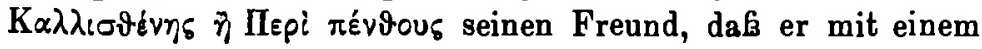
Manne zusammengestoßen sei, der mit seinem Glücke nichts anzufangen gewufst habe. Direkt ist damit zwar über Kallisthenes nichts gesagt, aber es wurde doch dabei der Gegensatz des Philosophen zu dem Könige in der Einschätzung seiner Person zum Ausdruck gebracht, indem die Maklosigkeit des Königs als das Verhängnis des Kallisthenes bezeichnet wurde ${ }^{19}$ ).

19) IS $12, \pi$.

15) Plut. Al. c. 55.

18), VIII $5,10 \mathrm{ff}$.

16) Cicero Tusc. III 21 : Theophrastus interitum deplorans Callisthenis sodalis sui dicit Callisthenem incidissee in hominem summa potentia
13) 10,1 . 10) Al. c. 52

14) Arrian IV 10,3.

17) IV 10,6 ff. 
Wenn die überlieferten Urteile über den Charakter des Kallisthenes und die Angaben uber sein Verhalten gegen den König sich nur zum Teil auf bestimmte Gewährsmänner zurückführen lassen und im einzelnen davon kaum etwas sicher und zuverlässig ist, so liegt ihnen doch offenbar eine gewisse allgemeine Wabrheit zugrunde, insofern sie schlieflich auf bestimmte Eindrücke von der Persönlichkeit, auf die sie sich beziehen, zurückgehen. Kallisthenes muß von der Umgebung Alexanders als ein Mann geschätzt sein, der, freiheitlich gesinnt, den Ansprüchen Alexanders auf göttliche Ehrung durchaus abgeneigt war, von einigen sogar für fähig gehalten wurde, von der Gesinnung zur Tat uberzugehen, und es kann kaum bezweifelt werden, dak er bei irgend einer Gelegenheit auf irgend eine Weise der Proskynesis tatsächliches Widerstreben entgegengesetzt hat.

Nur eine Aeuferung, die dem Kallisthenes bei Arrian untergelegt wird, zeigt ihn von einer andern Seite, dem Könige zugleich schmeichelnd und sich über ihn erhebend. Er sei nicht zu Alexander gekommen, um sich von ihm Ruhm zu erwerben, sondern um ihn berühmt zu machen. Denn der Glaube an seine Göttlichkeit hänge nicht von den Lügen der Olympias ab, sondern von dem was er in seiner Schrft uber Alexander und die 'Menschen gebracht habe (Arrian IV 10, 17). Diese alberne Bemerkung, eine plumpe Uebertragung des bekannten Topos über das Verhältnis des Dichters zu seinem Helden auf den Historiker, von Arrian selbst bezweifelt, enthält, wie wir später zeigen werden, einen Anachronismus, indem sie voraussetzt, daG das Werk des Kallisthenes über Alexander bereits in den Händen des Publikums war, als es kaum hätte begonnen sein können. Sie steht in Widerspruch zu allem, was sonst über die Persönlichkeit des Kallistheres berichtet wird, und kann nur aus der Voraussetzung ervachsen sein, deren Richtigkeit es eben zu prüfen gilt.

Unsicher und unklar ist auch die Ueberlieferung über die Gründe, die den Kallisthenes in das Heerlager slexanders führten. Nach Justin XII 6,17 hatte Alexander ihn be-

summaque fortuna, sed ignarum quemadmodum rebus secundis uti conveniret. 
rufen, um seine Geschichte zu schreiben. Auch nach der eben besprochenen Stelle bei Arrian war er zu diesem Zwecke zu Alexander gekommen, aber wohl nicht von ihm berufen, sondern aus eigenem Antrieb.

Ein ganz anderes Motiv gibt Plutarch Al. c. 53 an. Kallisthenes habe den Ehrgeiz gehabt, seine Mitbürger zurückzuführen und seine Vaterstadt neu zu besiedeln. Ebenso sagt er De Stoic. repugnantiis p. 1043 D, Kallisthenes habe gehofft, Olynth wieder aufzurichten wie Aristoteles Stagira.

Nach Suidas gab Aristoteles den Kallisthenes Alexander zum Begleiter, also doch wohl bei seinem Uebergang nach Asien. Auch nach Laertius Diogenes V 4 wurde Kallisthenes Alexander durch Aristoteles vorgestellt, nachdem er selbst von ihm die Wiederaufrichtung von Stagira erwirkt hatte. Dieser Zusammenhang erinnert an Plutarch und macht es wahrscheinlich, daß in der Quelle des Laertius dasselbe Motiv für die Verbindung des Kallisthenes mit Alexander angegeben war. $\mathrm{Da}$ aber die Vorstellung unmittelbar vor der Rückkehr des Aristoteles nach Athen stattfand, welche nach V 10 ol. 111, $2=335 / 4$ erfolgte, so hätte ja dann Kallisthenes gar nicht mit nach Asien zu gehen brauchen. Da er aber dort tatsächlich 327 war, so mükte doch zu dem einen noch ein zweites Motiv angenommen werden. Nun sagt Laertius V 10, Aristoteles habe durch seine Empfehlung des Kallisthenes Anstob bei Alexander erregt. Diese Bemerkung hätte keinen rechten Sinn, w'enn Alexander jahrelang an Kallisthenes nichts auszusetzen gefunden hätte, während sie eine ganz andere Bedeutung empfängt, wenn der Unwille des Königs bald nach der ersten Begegnung ausbrach. Da nun Laertius Diogenes dem Aristoteles eine Bemerkung in den Mund legt, die er nach seiner Meinung offenbar bald nachdem er den Kallisthenes vorgestellt hatte getan haben soll, während sie in Wirklichkeit die Ereignisse in Baktrien zur Voraussetzung hat, so werden wir wohl auch in bezug auf die Zeit der Empfehlung einem Irrtum annehmen dürfen und vermuten, daE sie schriftlich war und Kallisthenes erst später zu Alexander stieb.

Nun lieGen sich ja die beiden verschiedenen Motive leicht vereünigen. Man könnte sagen, Kallisthenes habe sich aller- 
dings Alexander zunächst empfehlen lassen, um seiner Vaterstadt zu nützen. Dann aber sei bei Alexander der Wunsch erwacht, daß Kallisthenes ihn begleiten möge, um seine Geschichte zu schreiben. Allein das wäre doch nichts anderes als jene Art billiger Harmonistik, die wir den Theologen so übel nehmen. In Wirklichkeit lassen sich zwei ursprünglich getrennte Ueberlieferungen unterscheiden, die man nicht voreilig vereinigen darf, ohne ihre Voraussetzungen untersucht zu haben. Plutarch sagt nichts davon, daß Kallisthenes nebenbei auch noch die Absicht gehabt habe, die Geschichte Alexanders zu schreiben, wohl aber sagt er unzweideutig, dak Kallisthenes Alexander ins Innere von Asien nachgezogen sei :

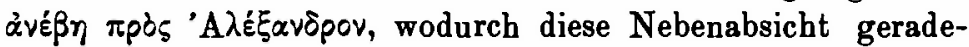
zu ausgeschlossen wird. Ja sogar bei Justin, der das andere Motiv der Reise des Kallisthenes zugrunde legt, finden wir die Voraussetzung, daß Kallisthenes erst in Baktrien zu Alexander gestoßen sei ${ }^{20}$ ). Auch nach einer von Ammianus Marcellinus XVIII 3, 7 wiederholten Anekdote bei Valerius Maximus VII 2, 11 stellte Aristoteles den Kallisthenes nicht persönlich vor, sondern schickte ihn zu Alexander.

Die äuferen Zeugnisse, daß Kallisthenes sofort mit Alexander als sein auserwählter Historiograph ins Feld gezogen sei, sind also sehr schwach. Wäre in ihnen die ältere Ueberlieferung enthalten, so wäre kaum zu begreifen, wie daneben die Erzählung bei Plutarch hätte aufkommen sollen, besonders da sie ja das unter dem Namen des Kallisthenes bekannte Geschichtswerk gegen sich hatte. Es läkt sich aber auch beweisen, daß die Ueberlieferung ron dem nachträglichen Eintreffen des Kallisthenes bei Alexander bis in seine Zeit selbst zurückgeht.

Chares hat, wie schon erwähnt, die versteckten Drohungen in dem wirklichen oder angeblichen Briefe Alexanders ${ }^{21}$ )

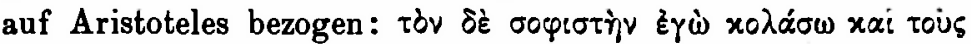

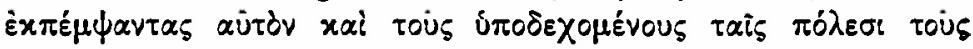

$\left.{ }^{20}\right)$ Iustin. XII 6, 17: multum profuere Callisthenis philosophi preces (nach der Ermordung dès Clitus), condiscipulatu apud Aristotelem familiaris illi, et tunc ab ipso rege ad prodenda memoriae acta eius acciti.

21) Plutarch Al. c. 55. 


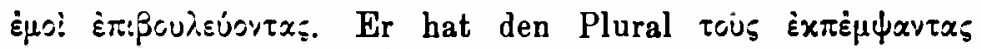

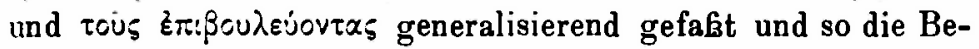
ziehung auf Aristoteles darin gefunden. Dann muk er unter denjenigen, die Alexanders Feinde bei sich aufnahmen, die Athener verstanden haben. Das stimmt mit den dem Kallisthenes untergeschobenen Versicherungen, die Athener würden den Mörder Alexanders bei sich aufnehmen und ihm Schutz gewähren (Arrian IV 10,4), die wohl eine in mazedonischen Kreisen tatsächlich vorhandene Stimmung gegen Athen widerspiegeln. Schon Chares ist also von der Voraussetzung ausgegangen, dak Kallisthenes, von Aristoteles mit Empfehlungen ausgeriustet, Alexander von Athen aus nachgereist sei.

Dak Alexander wirklich den ungeheuerlichen Verdacht gehabt habe, Aristoteles habe ihm durch seinen Neffen Nachstellungen bereiten wollen, und er daher, wie Chares behauptete, die beiden miteinander habe konfrontieren wollen, erscheint ganz unglaublich, wenn es auch nicht ausbleiben konnte, daß seine Erbitterung gegen den Neffen eine Verstimmung gegen den Onkel in ihm erzeugte, die sich gelegentlich auch in einer unmutigen und ungerechten Aeukerung Luft machen mochte, um so weniger, als sich nicht verkennen liek, daß die Auffassung des Kallisthenes sich in dem Punkte, der den Hauptanstok zu der Entfremdung zwischen ihm und dem Könige gegeben hatte, mit der des Aristoteles deckte. Denn wie hätte nicht auch Aristoteles, der seinem frủheren Zögling noch jüngst den Rat gegeben hatte ${ }^{22}$ ), in der Behandlung der Griechen und Perser den denkbar schärfsten Unterschied zu machen, diese als Tiere und Pflanzen, jene aber als Freunde und Angehörige zu betrachten, die Absicht den Griechen die orientalische Sitte der Proskynesis aufzuzwingen verdammen sollen?

Aus der Auffassung, daß Kallisthenes im Auftrage des Aristoteles gegen Alexander konspiriert habe, ging dann später der absurde Klatsch hervor, Aristoteles habe aus Furcht vor den Folgen der Entdeckung dieser Umtriebe dem Antipater ein Gift verschafft, das dieser durch seinen Sohn Alexander

22) Strabo I p. 66 (Arist. fr. 81). 
habe eingeben lassen ${ }^{23}$ ). Erst im sechsten Jahre nach dem Tode des Königs wagte sich dieser Klatsch, wie Plutarch berichtet ${ }^{24}$ ), ans Licht. Damals wird man auch erfunden haben, dá Alexander einen Versuch Kassanders, seinen Vater gegen gewisse Beschuldigungen zu verteidigen, als Sophismata des Aristoteles gebrandmarkt habe ${ }^{25}$ ).

Vielleicht ist es Chares gewesen, der diese Dinge zuerst in die Literatur gebracht hat. Wenigstens stimmt die Erzählung, daß Aristoteles wegen des Kallisthenes für sich gefürchtet habe, zu seiner Angabe, Alexander habe die beiden einander gegenüberstellen wollen.

Dieses ganze Lügengewebe hätte gar nicht entstehen können, wenn Kallisthenes den König von Beginn seiner Feldzüge an als Historiograph begleitet hätte. Denn damals herrschte zwischen dem Könige und seinem Lehrer das beste Einvernehmen. Der Gedanke, daßs Kallisthenes ein geheimer Agent des Aristoteles sei, konnte erst aufkommen, wenn Kallisthenes bei dem Könige eintraf, als er von den griechischen Sitten mehr und mehr abzufallen und sich als orientalischen Herrscher zu fühlen begann.

Wenn der Gedanke, daßs Kallisthenes von vornherein der berufene Historiograph Alexanders war, gar nicht in der ältesten Ueberlieferung wurzelt, so kann er nur auf Grund des dem Kallisthenes zugeschriebenen Werkes über Alexander entstanden sein. Dieses mufte ihn unmittelbar ergeben.

Der Titel dieses Werkes war nach allgemeiner Annahme

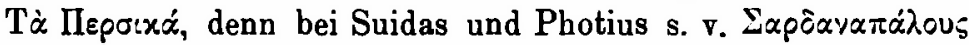
u. a. wird eine Stelle aus dem $\mathbf{z w e i t e n ~ B u c h e ~ d e r ~ P e r s i c a ~}$ des Kallisthenes angeführt, die man diesem Werke zuzurechnen pflegt. Ueber diese Stelle werde ich später besonders bandeln. Schon hier aber mus bemerkt werden, dak

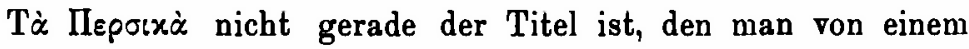
Werke zum Ruhme Alexanders erwartet, das in keiner Weise

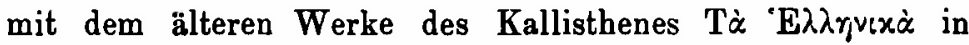
Parallele gestellt werden konnte. In den Briefen Ad Familiares V 12, 2 setzt Cicero dem mit einer römischen Geschichte von

29) Arr. VII 27.

21) Alex. c. 77 .

25) c. 74 . 
Beginn der Bürgerkriege an beschäftigten L. Lucceius zu, von dem fortlaufenden Gescbichtswerk getrennt die katilinarische Verschwörung zu behandeln, wofür er ihn auf den Vorgang der Griechen verweist: ut multi Graeci fecerunt, Callisthenes Troicum bellum, Timaeus Pyrrhi, Polybius Numantinum, qui omnes a perpetuis suis historiis ea quae dixi bella separaverunt. Offenbar ist Troicum verderbt. Da nun nach dem Zeugnis des Athenaeus XIII p. 560 c Kallisthenes ein Buch Пep: тou

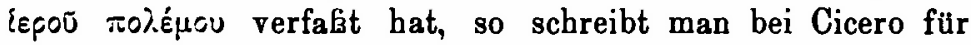
Troicum nach dem Vorgange von Westermann Phocicum. Allein das entspricht dem Sinn der Briefstelle nicht recht. Denn da Kallisthenes seine Hellenica bis an den Ausbruch des heiligen Krieges herabführte, so schlok das eine Geschichtswerk inhaltlich unmittelbar an das andere an. Sehr wahrscheinlich ist daher das zweite erst nach Vollendung des ersten geschrieben worden. Sollte es aber nicht der Fall gewesen sein, so wird Cicero schwerlich davon Kenntnis gehabt haben. Ihm kommt es auf Beispiele von Historikern an, die ibre Arbeit unterbrachen, um auferhalb der Reihe einen einzelnen Helden zu feiern. Dazu würde das Werk des Kallisthenes über Alexander d. Gr. passen. Sollte daher nicht vielmehr Persicum ${ }^{26}$ ) für Troicum statt Phocicum zu lesen

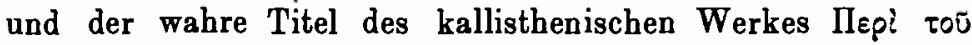

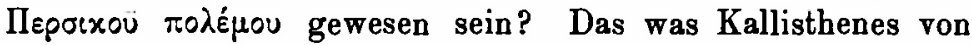
der Geschichte Alexanders erlebt hatte, reichte gerade bis zum Ende des persischen Krieges im engeren Sinne, bis zu dem Beginn der Unternehmungen gegen Indien.

Das Werk des Kallisthenes hatte ganz offen die Verherrlichung Alexanders zum Zweck. Polybius nimmt den Kallisthenes wegen dieser Tendenz in Schutz. Er erklärt es für durchaus berechtigt, einen Mann von übermenschlicher Naturanlage für einen Gott zu erklären (ảmov๖oüv). Diese Auffassung steht durchaus in Einklang mit der des Aristoteles, der es auch für Unrecht erklärt, einen durch persönliche Eigenschaften und politische Macht überragenden Menschen mit

2s) Cicero sagt bellum Persicum ebenso für Perserkrieg (Lael, 42) wie tür Krieg mit Perseus (De off. I 37). 
den andern auf eine Stufe zu stellen, da ein solcher billigerweise wie ein Gott unter Menschen angesehen werden müsse ${ }^{27}$ ).

Allein zwischen einer solchen Würdigung und der Verehrung eines Menschen als Sohn des höchsten Gottes und als ein durch göttliche Zeichen jeder Art bezeugtes göttliches Wesen ist doch ein wesentlicher Unterschied. Von dieser Art aber war die Schätzung, die Alexander in dem kallisthenischen Werke zuteil geworden war. Als die Fuhrer auf dem Zuge nach dem Ammonium den Weg verloren, erzählte Kallisthenes, da erschienen zwei Raben, um die Führung zu übernehmen. Von diesen Raben als göttlichen Boten erzählte freilich auch Aristobulos, während Ptolemaeus an ihre Stelle zwei Schlangen setzte ${ }^{28}$ ). Aber bei Kallisthenes war das

27) Pol. ILI 13 p. 1284 a.

${ }^{28)}$ Die Variante des Ptolemaeus scheint vereinzelt gewesen zu

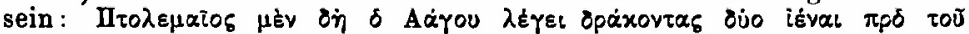

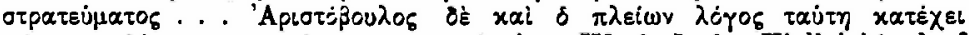

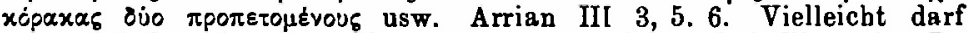
man auf Grund dieser Variante eine Anekdote bei Plutarch, De Alexandri fortuna aut virtute c. 7 p. 339 F (vgl. Al. c. 48) auf Ptolemaeus zurückführen. Hier wird erzählt, daf Philotas sich in seinen Keden seiner Geliebten gegenuber, sebr frei babe geben

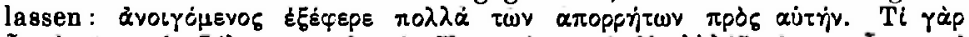

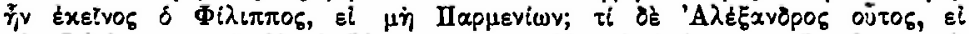

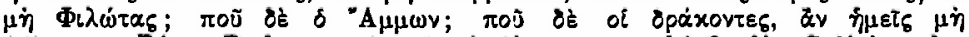
$\oint \varepsilon \lambda \omega \mu \varepsilon v ;$ Diese Reden vertraute Antigona, so hies die Geliebte des Philotas, einer ihrer Bekannten an, die sie an Krateros weitergab, Krateros aber fübrte Antigona heimlich zu Alexander. Alexander befahl ihr, mit Philotas weiter im Verkehr zu bleiben und ihm Mitteilung zu machen von allem, was sie von ihm hören würde. So erfuhr Alexander, wie es in der Vita c. 49 heikt, was Philotas im Zorn und in der Ueberbebung gegen ihn sagte. Trotz dieser stäken Beschuldigung häbe Alexander geschwiegen, sei es im Vertrauen auf die Ergebenheit des Parmenion, sei es aus Furcht vor

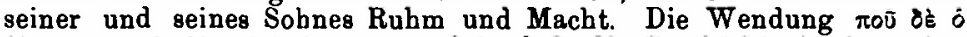

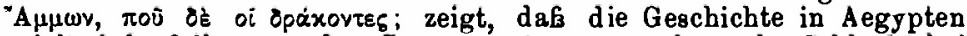
spielt, jedenfalls nacn dem Zuge zum Ammon und vor der Schlacht bei Gaugamela. Nach Arrian III 25, 8 berichteten Ptolemaeus und Aristobulos, dak Alexander bereits in Aegypten Anzeige von Umtrieben des Philotas bekommen habe, die ihm aber wegen ibrer alten Freundschaft und der Ehre, die er dem Vater Parmenion, und des Vertrauens, das er dem Philotas selbst erwiesen habe, nicht glaubhaft erschienen sei.

Ist meine Vermutung richtig, so hat Ptolemaeus sehr viel ausführlicher und lebhafter über das Schicksal des Philotas berichtet als man nach Arrian vermuten konnte. Die Differenzen $\mathrm{zwischen}$ Arrian und Plutarch - Alexander erscheint bei diesem sehr viel mifstrauischer - mögen auf Aristobulos' Rechnung zu setzèn sein und betreffen nicht den Kern der Sache. Mit dem summarischen Bericht 
Wunder noch weiter ausgeschmückt. Bald zogen sie voran, bald warteten sie auf die Zurückbleibenden, des Nachts aber sammelten sie durch ihr Geschrei die Verirrten und brachten sie wieder auf die richtige Spur. Während aber weder Aristobulos noch Ptolemaeus zu sagen wukten, welche Auskunft der Gott dem Könige gegeben babe ${ }^{29}$ ), erzählte Kallisthenes ganz bestimmt, dak der Prophet ihn sogleich als Sohn des Zeus angeredet und außerdem bestimmt versichert habe, dak sein Vater kein Sterblicher sei ${ }^{30}$ ). Damit begnügte sich aber Kallisthenes nicht. Zu derselben Zeit, erzählte er weiter, sei die seit der Zerstörung des Branchidenorakels durch die Perser versiegte Quelle wieder emporgesprudelt und die Gesandten der Milesier hätten viele Orakel nach Memphis gebracht, über die Zeugung Alexanders durch Zeus, über den zukünftigen Sieg bei Arbela, den Tod des Dareios und den Abfall der Lacedämonier. Auch wufite er zu berichten, daß die Erythräerin Athenaïs, die der alten erythräischen Sibylle ähnlich gewesen sei, die göttliche Geburt des Königs verkundet habe ${ }^{31}$ ).

Als Sohn des Zeus erwiesen ihn dann nach Kallisthenes auch seine T'aten. In der Schlacht bei Gaugamela, erzählte er, babe Alexander die Götter angerufen, sie sollten durch ihren Beistand beweisen, daß er wirklich Sohn des Zeus sei ${ }^{32}$ ).

Alle Schmeicheleien des Buches wurden aber bei weitem ubertroffen durch die Schilderung des berthmten Marsches Alexanders über den schmalen, den Meereswogen preisgegebenen Küstensaum hart am Rande der pamphylischen Berge. Das Meer erkannte seinen Herrn, hiek es in der Schrift des Kallisthenes, und die wallenden Wogen vollzogen, indem sie sich vor ihm bückten, die Proskynesis ${ }^{33}$ ).

Es ist klar, daß̧ die Stelle uber die Orakel nicht vor

Arrians äber den Prozeß selbst, für den er Ptolemaeus allein als Gewährsmann nennt, stimmt die ausfahrliche Schilderung bei Plutarch c. 49 therein.

29) Arr. III 4, 5.

s: Plut. Al. c. 33.

30) Plut. Al. c. 27.

31) Strabo XVII 814.

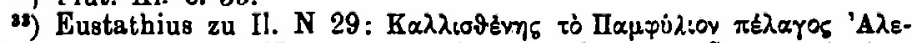

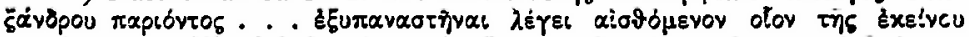

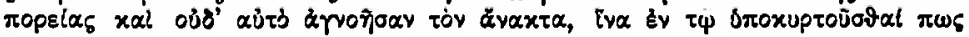

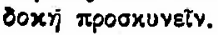


ihrer Erfüllung geschrieben sein kann, und schwerlich ist der Gedanke, der in dem Spiel der Wogen eine Reverenz vor dem Könige erkannte, konzipiert, bevor der König diese Reverenz von seinen Untertanen forderte oder doch sein Wunsch, sie eingeführt zu sehen, erkannt war. Denn welche stärkere Empfehlung dafür lieke sich denken als die Erkenntnis, dak sogar die stumme Natur dem Könige als einem Gotte huldigte? Die allmähliche Umwandlung der Hofhaltung Alexanders begann nicht vor dem Tode des Darius. Nach unseren Quellen wurden die Versuche, die Proskynesis als allgemein verbindliche Hofsitte einzuführen, einige Zeit nach der Ermordung des Kleitos unternommen. Nicht früher als während der Winterrast in Zariaspa von 329 auf 328, wenn Kallisthenes den Wünschen Alexanders vorauseilte, kann also die Stelle über die Huldigung der Meereswogen geschrieben sein.

Wie sollen wir das reimen mit den Schlüssen, die wir aus unsern ältesten Nachrichten auf das Wesen und den Charakter des Kallisthenes ziehen müssen? Kann er das, was er verabscheute, in seiner Schrift sogar inauguriert haben, oder kann er es mit der Feder verherrlicht haben, während er es mit Worten tadelte? War er aber der offizielle Hofhistoriograph, so war doch das, was er schrieb, unmittelbar für das $\mathrm{Ohr}$ des Königs und das seiner Ungebung bestimmt.

Diese Gegensätze sind nicht zu vereinigen. War Kallisthenes der Mann, als welcher er nach der Ueberlieferung erscheint, so kann er das Buch, das ihm zugeschrieben wird, nur als Palinodie geschrieben haben. Er wäre nicht der erste gewesen, der aus Furcht vor dem Tode seine Ueberzeugung verleugnet und, um sein Leben zu retten, seine Grundsätze geopfert hätte; nur mubte er, wenn er den Willen dazu hatte, auch die Möglichkeit haben, ihn auszuführen.

Nach der glaubhaften Angabe des Chares hat Kallisthenes noch sieben Monate gelebt, nachdem die Katastrophe über ihn hereingebrochen war. Aber wie hätte er es anfangen sollen, die Geschichte Alexanders zu schreiben, wenn er, wie Aristobulos berichtete, in Fesseln mit dem Heere mitgeschleppt wurde? Man braucht die Nachricht, die sich zuerst 
bei Ovid nachweisen läkt, nicht zu glauben, daß Alexander den unglücklichen Mann in einen Käfig gesteckt habe ${ }^{34}$ ), aber wenn wir dem Chares glauben, dak Kallisthenes erst im Lande der Maller gestorben sei, so müssen wir ihm auch glauben, daß sein Tod in einem Zustand völliger Verwahrlosung infolge der abscheulichen Krankheit eintrat, die auch der von

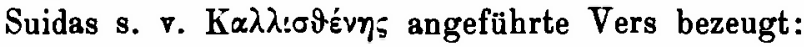

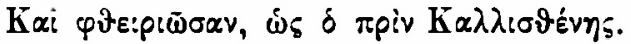

So läkt sich die Autorschaft des Kallisthenes an dem ihm zugeschriebenen Buche nicht einmal durch eine Verlegenheitshypothese mit der Ueberlieferung über seine Person in Einklang setzen.

Wenn die älteren Berichterstatter dieses Buch zu seiner Beurteilung offenbar weder im günstigen noch ungünstigen Sinne gebraucht haben, so ist den Späteren der Kontrast zwischen den Huldigungen des Buches und dem Verfahren Alexanders gegen seinen angeblichen Verfasser nicht unbemerkt geblieben.

Einen scharfen epigrammatischen Ausdruck hat Ovid dafür gefunden, Ibis 521

Inclususque necem cavea patiaris, ut ille non profecturae conditor historiae.

Es muß auch eine Auffassung gegeben haben, daßs Kallisthenes das Buch um Lohnes willen geschrieben habe, denn das Urteil Arrians, daß alle, die zu Lebzeiten Alexanders seine Geschichte behandelt hätten, durch den Zwang, dem König zu gefallen, und den Wunsch, von ihm belohnt zu werden, gebunden gewesen seien, muk in erster Linie auf Kallisthenes bezogen werden, dessen Schrift Arrian, wie schon bemerkt, nicht unbekannt war.

Keiner hat das Buch stärker verurteilt als Timaeus ${ }^{35}$ ). Er warf Kallisthenes vor, den Charakter Alexanders verdorben zu haben, und sah in seinem Schicksal die gerechte Strafe für die Schmeicheleien seines Buches, denen er die Haltung des Demosthenes und der übrigen Redner gegenüberstellte, die sich den Anträgen auf die Bewilligung göttlicher Ehre

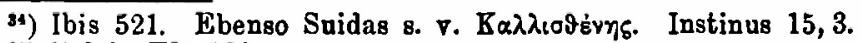

3E) Polyb. XII $12 \mathrm{~b}$. 
für Alexander widersetzten. So sehr hatte bei ihm der Eindruck des Buches die Erinnerung an die Schilderung der Persönlichkeit des Kallisthenes verdrängt. Aber widerlegt hat er die Ueberlieferung offenbar nicht, er hat sie nur ignoriert. Wie aber hätte dieser starke Eindruck des Buches eine Ueberlieferung aufkommen lassen, die ihm so vollkommen widersprach? Es ist schon merkwürdig genug, daß der Fälscher des Buches es wagte, sich zu dieser Ueberlieferung in Gegensatz zu stellen, aber daß sich um den Verfasser eines solchen Buches schon alsbald nach seinem Tode in dem Kreise der Leute, mit denen er zusammen gelebt hatte, eine Legende hätte bilden sollen, die ihn in den Ruf des Freimuts und der Gesinnungstüchtigkeit brachte, das scheint mir geradezu unmöglich.

Aber die Ueberlieferung, die den Kallisthenes aus patriotischen Gründen Alexander aufsuchen und sich erst in Innern von Asien mit ihm vereinigen läßt, hat, wie es scheint, nichts weniger als ein Selbstzeugnis des Kallisthenes gegen sich, nach welchem er schon in Aegypten bei Alexander gewesen sein müGte. Allein dies scheinbare Selbstzeugnis enthält große Schwierigkeiten und kann nicht ohne eine eingehende Untersuchung, die es übrigens um seines Inhalts willen auch an sich verdient, für die gegenwärtige Frage verwendet werden. Ich habe es daher bis jetzt beiseite gelassen, um es mit derjenigen Ausführlichkeit, die mir wünschenswert scheint, behandeln zu können.

In einer Aufzählung von Ansichten über die Ursache der alljährlichen Anschwellung des Nils gibt Iohannes Lydus De mensibus IV 107 S. 146 ed. Wuensch an, Kallisthenes berichte im 4. Buche seiner Hellenica, er sei, als er mit Alexander d. Gr. zu Felde gezogen sei, nach Aethiopien gekommen und habe gefunden, das dort der Nil aus unendlichen Regengüssen

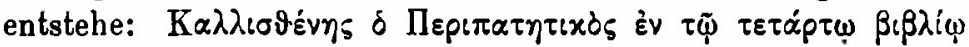

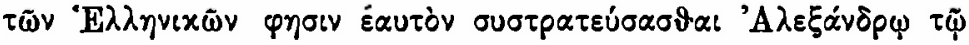

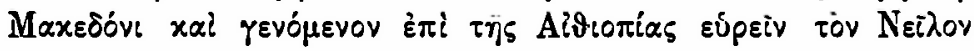

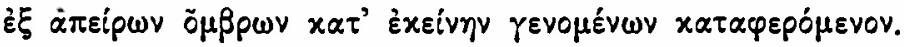

Diese Nachricht klingt so unglaublich, dak man ange- 
nommen hat, durch Irrtum sei im Laufe ihrer Uebermittelung aus einem bloßen Bericht des Kallisthenes über das, was er in Aegypten gehört habe, ein eigenes Erlebnis gemacht worden ${ }^{36}$ ).

Angenommen, daß Kallisthenes tatsächlich mit Alexander in Aegypten gewesen sei, so hat ihn allerdings der Feldzug Alexanders nicht uber die Südgrenze Aegyptens hinaus nach Aethiopien geführt. Curtius, der einzige, der Alexander von Memphis aus auf dem $\mathrm{Nil}$ in das Innere Aegyptens vordringen läß̧t, irrt sich in der Richtung, wie Arrian zeigt ${ }^{37}$ ). Er selber aber sagt, daß dem Wunsche des Königs, auch Aethiopien zu besuchen, die Sorgen des Krieges ein Ziel gesetzt hätten ${ }^{38}$ ). Daß er zusammen mit dem Könige nach Aethiopien gekommen sei, läßst nun freilich Iohannes Lydus den Kallisthenes auch nicht sagen, aber daß Kallisthenes aus eigenen Stücken oder auf Befehl des Königs eine Forschungsreise nach dem Süden gemacht habe, ist ebenfalls ausgeschlossen.

Die Ansicht des Kallisthenes uber den Nil begegnet uns in der doxographischen Literatur auch bei dem Anonymus

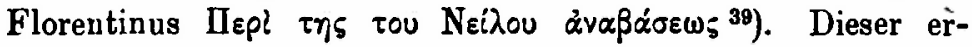
gänzt die Angabe des Iohannes Lydus dahin, daßs die Regengüsse, die das Steigen des Nils bewirkten, aus den Wolken sich ergössen, die von den zwischen dem Aufgehen des Hundssternes und dem des Arkturos wehenden Passatwinden nach

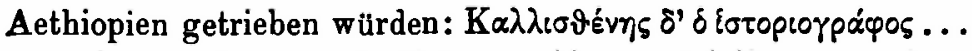

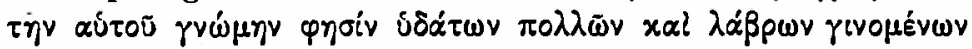

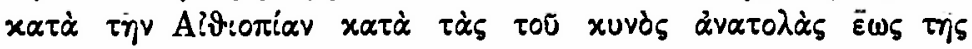

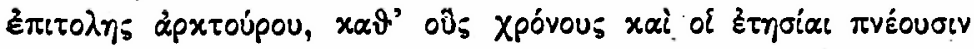

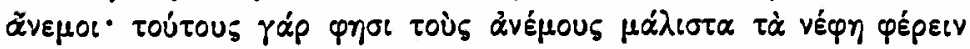

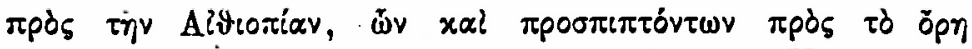

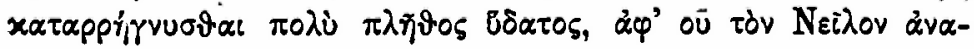

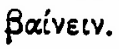

Kallisthenes müate also, wenn er selbst die Regengüsse

as) So Rose Aristoteles Pseudepigraphus S. 241 und Diels Seneca nnd Lucan, Abh. der kgl. Akad. d. Wiss. Berlin 1885, S. 20.

37) Vgl. Curtius IV 7, 5 und Arrian III 1, 5.

s8) Curtius IV 8, 3 .

s9) Von Schweighäuser in seinem Athenaeus hinter Buch II abgedruckt, darnach auch von Meinek'e Athen. II 87.

Pbilologus LXXIV (N. F. XXVIII), 1. 
in Aethiopien beobachtet hätte, im Sommer 331 dort gewesen sein. Um diese Zeit stand aber Alexander bereits am Euphrat. Wenn er aber den Kallisthenes als seinen Hofhistoriographen mitgenommen hätte, so würden wir doch wohl annehmen dürfen, dak er ihn nicht in Aethiopien physikalische Fragen studieren ließ, während er selbst zum vernichtenden Schlage gegen die Perser ausholte.

Wie hätte es aber Kallisthenes im Lager Alexanders wagen können, seine griechische Geschichte so zu ändern oder zu erweitern, wie er es getan haben müfte, wenn die Ueberlieferung über ihn richtig wäre? Er hätte diese Aenderung oder Erweiterung sorgfältig verborgen halten müssen, weil ihn ja jeder in dem Gefolge Alexanders hätte widerlegen können. Wie soll man sich aber dann vorstellen, dak der Zusatz in die Hellenica uberhaupt hineinkam, da ja doch diese längst vervielfältigt und verbreitet waren? War der Zusatz wirklich von ihm selbst, so konnte er doch nur von einem anderen nach seinem Tode in die Hellenica eingeführt sein. Wozu aber hätte Kallisthenes die ganze Geschichte erfinden sollen, wenn er doch nicht die Freude haben konnte, sie selbst unter die Leute zu bringen?

Wie wenig aber Alexander und seine Umgebung während seines Aufenthalts in Aegypten sich um die Frage nach den Quellen des Nils und den Ursachen seines Steigens gekummert hatte, läft sich aus den Fragmenten der zeitgenössischen Historiographen noch erkennen. Dürfen wir Nearch glauben, so war Alexander darüber völlig im Unklaren. Denn als er im Indus Krokodile und am Akesines ägyptische Bohnen sah, glaubte er die Quellen des Nils entdeckt zu haben. So Strabo XV p. 696 nach Nearch. Arrian, der wohl derselben Quelle folgt, setzt hinzu, Alexander habe das auch an Olympias geschrieben, später aber, als er seinen Irrtum erkannte, den Satz aus dem Briefe herausgenommen ${ }^{40}$ ).

Nearch beruhrte an derselben Stelle, an der er von der irrtümlichen Vorstellung Alexanders erzählte, auch das alte Problem der Nilanschwellungen und wandte darauf.die Er-

40) VI 1, $4 \mathrm{f}$. 
fahrungen, die man an den indischen Strömen gemacht hatte, an. Dasselbe tat auch Aristobulos. Auch er verglich die Verhältnisse in Indien mit denen in Aegypten und beide waren darin einig, daE die gleichzeitig in Indien und Aegypten einsetzenden Anschwellungen der Flusse dieselben Ursachen hätten, nämlich die gewaltigen Regengüsse in den Bergen, nur dak diese in Indien von Norden, in Aegypten von Suden kämen. Dabei haben sie aber offenbar aber die Ursachen der Regenbildung in dem heißen Aethiopien keine Betrachtungen angestellt, sondern unter dem Eindruck ihrer Erfahrungen in Indien ohne weiteres analoge Verhältnisse in Oberägypten und Aethiopien vorausgesetzt. Dies tut auch der unter dem Einfluf der Historiographen Alexanders schreibende Agatharchides, der bei Diodor erklärt, es sei durchaus kein Grund, sich uber die sommerlichen Regengůsse in Aethiopien zu verwundern, weil sie am Hydaspes in derselben Weise einträten ${ }^{41}$ ).

Alexander und seine Umgebung haben also erst in Indien angefangen sich Gedanken aber das alte Problem der Nilquellen und Nilanschwellungen zu machen und die Geschichtsschreiber Alexanders haben erst bei der Beschreibang der indischen Flüsse taber den Nil gehandelt. Sie haben nicht auf Grund irgend welcher durch Alexander veranlakten Untersuchungen an Ort und Stelle geurteilt, und wenn man zwar auch schon vor ihnen das regelmäkige Eintreten von Regengüssen zur Sommerzeit in Aethiopien angenommen hatte, so war es doch für sie eine neue Erkenntnis und die Umgebung Alexanders wufte nichts davon, daE Kallisthenes dies Problem während der Feldztige behandelt hatte.

Allein wenn die uberlieferte Tatsache unmöglich ist, so hängt doch die Ueberlieferung selbst so eng mit der Frage nach dem Verhältnis des Kallisthenes zu Alexander zusammen, daß, wenn wir diese nach allen Seiten klären wollen, wir wenigstens den Versuch machen müssen zu erforschen, wie diese Ueberlieferung entstehen konnte und was etwa Kallisthenes in den Hellenica tatsächlich gesagt haben mag.

4) Diod. I 41. 
Die Nachricht des Iohannes Lydus stammt höchst wahrscheinlich aus Senecas Naturales Quaestiones. Durch den Augenschein erweist sich der doxographische Abschnitt bei Seneca IV a 2, 17-30 über die Ursachen der Nilansch wellungen als Quelle für Iohannes IV 107 p. 144, 11-146, 3. $\mathrm{Er}$ nennt auch selbst Seneca als seinen Gewährsmann für die von ihm an erster und zweiter Stelle angeführten Ansichten des Anaxagoras und Euthymenes ron Massalia, nicht mehr für Diogenes ron Apollonia, mit dem unsere Ueberlieferung des Seneca abbricht. Da Iohannes aber auch die Ansicht des Diogenes Wort für Wort aus Seneca entlehnt hat, so dürfen wir annehmen, dak er diesem auch die bei ihm folgenden Ansichten des Herodot, der Aegypter, des Ephoros, Thrasyalkes, Kallisthenes und Dikaiarchos verdankt.

Die Naturales Quaestiones sind, wie Diels in der Abhandlung der Berliner Akademie Seneca und Lucan 1886 gezeigt hat, auch ron Lucan im 10. Buche der Pharsalica benutzt worden.

V. 219-254, in denen die Ansichten des Anaxagoras, Thales und Diogenes behandelt werden, entsprechen Seneca N. Q. IV a 2, 17. 22.28.

Schwerer läkt sich über V. 255-261 urteilen. In V. 255-256 wird die Ansicht referiert, dak der Nil aus dem allumfassenden Ozeau entspringe ${ }^{42}$ ). Das entspricht der Ansicht des Euthymenes, der auf einer Fahrt durch das atlantische Meer in ihm den Ursprung des Nils entdeckt zu haben behauptete. Aber Diels hat darauf hingewiesen, dak der folgende V. 257, in welchem gesagt wird, das Meersalz habe in dem langen Lauf des Nils seine Schärfe verloren ${ }^{43}$ ), mit Euthymenes nicht stimme, der dem Einwand, den man von der Sücigkeit des Nilwassers entnehmen konnte, vielmehr mit der Behauptung begegnete, auch das Wasser des atlantischen Meeres sei süb. Gercke hat daher, in seiner Ausgabe der N. Q., die Verse auf die bei Iohannes an letzter Stelle aufgeführte Ansicht Dikaearchs zurückgeführt, der gleichfalls

42) Rumor ab Oceano, qui terras alligat omnes, exundante procul violentum erumpere Nilum.

42) aequoreosque sales longo mitescere tractu. 
den Ursprung des Nils aus dem atlantischen Meere behauptete. Aber damit wird V. 257 nicht erklärt. Dieser Vers stimmt aber z. T. wörtlich mit dem, was in der doxographischen Uebersicht in dem Schol. Apollonii IV 269 als Ansicht des Demokrit bezeichnet ist, wonach ebenfalls die Sübigkeit des aus dem Meere entsprungenen Nils aus der Länge seines Weges und dem Einfluß der Hitze erklärt wird. Da es sich aber um die Quelle des Nils nur insofern handelt, als sie für die Frage nach dem sommerlichen Steigen des Nils von Bedeutung ist, so geben V. 255-257 offenbar nur die Voraussetzung für die nun folgende Erklärung V. $258 \mathrm{ff}$.

nec non Oceano pasci Phoebumque polumque credimus. hunc, calidi tetigit cum bracchia cancri, sol rapit atque undae plus quam.quod digerat aer tollitur. hoc noctes referunt Niloque refundunt.

Die Sonne entzieht dem Ozean, sobald sie in das Zeichen des Krebses getreten ist, große Wassermengen, wovon die Nächte das von der Luft nicht verbrauchte Quantum wieder zurückbringen, das so in den aus dem Ozean entspringenden Nil gelangt. Wenn der Satz, durch den diese nichts weniger als deutliche Erklärung eingeleitet wird, zwar in seiner Allgemeinheit stoisch ist, so ist es die Anwendung davon keineswegs. Denn bei den Stoikern wird an eine Speisung durch beständige und gleichmäßige Ausdünstung des Ozeans gedacht, während der Ausdruck, daß̧ die Sonne den Ozean im Beginn des Sommers gewaltsam packt, auf eine naive und altertümliche Vorstellung schließen läßst. Auch hat kein Stoiker das Steigen des Nils mit der Ausdünstung des Ozeans in Verbindung gebracht, insbesondere nicht derjenige, von dem wir wissen, daß er sich eingehend mit jener Frage beschäftigt hat, Posidonius. Freilich kommt der Ausdruck sol rapit auch bei Seneca in der Wiedergabe der Ansicht des Diogenes vor. Aber da ist nicht der Ozean, sondern die Feuchtigkeit uberhaupt Objekt und mit der Hypothese des Diogenes, die Lucan V. 247-254 behandelt, hat diese letzte Hypothese nichts gemein als die Voraussetzung, dak der Nil aus dem Ozean entspringt. Doch ist es wohl nicht Zufall, daß̧ Lucan 
sie darauf folgen läßt; denn die Verbindung ist durch die gemeinsame Voraussetzung gegeben. Wahrscheinlich hat Seneca diese Hypothese, unter Angabe ihres Urhebers, in derselben Reihenfolge behandelt. Denn dak Lucan sich an dieser Stelle von Seneca entfernt haben sollte, nachdem er ibm von V. 219-254 ausschlieflich gefolgt war, ist an sich schon unwahrscheinlich. Dak aber Seneca noch andere Ansichten auker denen des Euthymenes und Diogenes berücksichtigte, die auf der Annahme beruhten, daG der Nil aus dem Ozean entspringe, geht aus Iohannes Lydus hervor, der seine Uebersicht mit der Hypothese des Dikaearch schliekt, dak der Nil aus dem atlantischen Meere aufgeschüttet werde. Diese Hypothese steht aber offenbar nicht an ihrem Platze, denn sie wird so eingeführt, daß sie sich ursprünglich an eine andere angeschlossen haben muk, mit der sie wenigstens einen Punkt

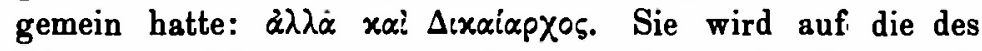
Diogenes gefolgt sein und es ist anzunehmen, dak Seneca mit ihm diejenige verbunden hatte, die in dem Scholion Apollonii dem Demokrit zugeschrieben wird.

Bei Lucan wird der Widerstreit der Meinungen von dem ägyptischen Priester, den er von V. 194 an reden läßt, durch eine religiöse Erwägung abgeschlossen. Aber wenn er sich den Anschein gibt, als wenn der Streit damit entschieden würde (V. 262 ast ego, si tantam ius est mihi solvere litem), so ist das irreführend, denn was er dann zum Besten gibt, dak der Nil zugleich mit der Welt geschaffen sei, hat ja mit dem Streit über die Ursachen der Nilanschwellungen gar nichts zu tun. Tatsächlich läbt er also diesen Streit unentschieden. Dasselbe mú auch Seneca getan haben, denn mit Recht hat Gercke auch die Schlubbemerkung des Iohannes

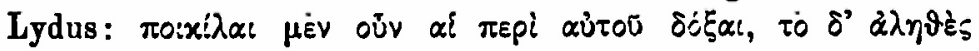

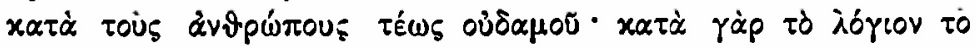

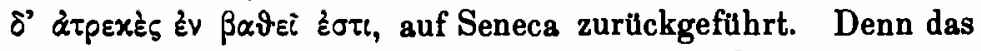
darin angeführte Zitat ist ein Lieblingswort Senecas, das er sowohl N. Q. VII 32, 4 als De benef. VII 1, 6 verwendet hat. Dak aber die Natur des Nils ein unaussprechliches Geheimnis bildet, sagt Seneca an eben dem Orte, von dem, wie Diels gezeigt hat (S. 18), Lucan die Weisheit entlehnt, die er dem 
ägyptischen Priester in den Mund legt, N. Q. III 22 . Derselbe Skeptizismus wird auch N. Q. IV 2, 2 ausgesprochen ${ }^{44}$ ).

Die Abhängigkeit des Iohannes Lydus von p. 144, 11 bis 147,6 und des Lucan ron X 219 bis 261 von dem 4. Buche der N. Q. des Seneca ist somit erwiesen und wir können Seneca statt des Iohannes als Gewährsmann für die Ansicht des Kallisthenes bezeichnen.

Lucan hat die Ansicht des Kallisthenes aus Seneca nicht mit aufgenommen, wie er ja den ganzen Abschnitt stark verkürzt hat, aber er spricht V. 272-274 von einer Expedition, die Alexander zur Erforschung der Quellen des Nils ausgesendet habe:

Summus Alexander regum, quem Memphis adorat, invidit Nilo, misitque per ultima terrae

Aethiopum lectos. Illos rubicunda perusti

zona poli tenuit, Nilum videre calentem.

Wir dürfen annehmen, daß Seneca über Kallisthenes mehr gesagt hat, als bei Iohannes Lydus steht. Denn dieser ist sehr flüchtig zu Werke gegangen. Anfangs berücksichtigt er auch Senecas Kritik an den einzelnen Ansichten, dann gibt er aber nur diese selbst in stark verkürzter Weise wieder. Es ist daher sehr wahrscheinlich, daß Seneca uber die Expedition des Kallisthenes nach Aethiopien ausführlicher gesprochen hat als Iohannes, aber doch ist es sehr unsicher, dak Lucan bei den eben angeführten Versen Seneca vor Augen gehabt hat.

Die Erörterungen über den Nil zerfallen bei Seneca wie bei Lucan in zwei ron einander unterschiedene Teile, einen beschreibenden úber den Lauf des Flusses und einen rein physikalischen über die Ursachen seines Steigens im Sommer. Bei Seneca geht der beschreibende, bei Lucan der physikalische voran. Von der Expedition Alexanders oder irgend einer andern Expedition ist bei Seneca in dem beschreibenden Teile keine Rede, bei Lucan beginnt dieser dagegen mit der Erzählung von den Versuchen Alexanders, des Sesostris und

4) Unde crescere incipiat si comprehendi posset, causae quoque incrementi invenirentur. 
Kambyses, die Quellen des Nils aufzusuchen. Ueberhaupt aber enthält der ganze erste Abschnitt dieses Teiles von V. 268-306 nichts, was sich auf Seneca zurückführen liefe, dagegen ist die Uebereinstimmung von V. 307 an wieder vollständig.

Nun könnte ja nichtsdestoweniger die Angabe über Alexander von Lucan aus dem doxographischen Teile, wo sie bei Seneca gestanden haben mükte, in den beschreibenden hinübergenommen sein, weil es ihm so besser in seine Disposition paßste. Aber dagegen spricht, wie mich dünkt, entscheidend, daß nach Lucan die Expedition ein negatives Ergebnis hatte, während ja nach Iohannes Lydus Kallisthenes seine Erklärung der Nilanschwellung gerade auf seine Erfahrung in Aethiopien gründete.

Die Naturales Quaestiones des Seneca beruhen, wie Diels in den Doxographi S. 19 festgestellt hat, hauptsächlich auf dem Material des Posidonius. Für unsern Fall wird das enge Verhältnis beider nach Diels' Nachweisungen noch durch einen besonderen Umstand bewiesen. Wie bei Iohannes Lydus, so waren nämlich auch bei Posidonius, wie sich aus Strabo XVII 790 ergibt, die Ansichten des Kallisthenes und Thrasyalkes eng miteinander verknüpft ${ }^{45}$ ).

Diese Strabostelle ist ein besonders wichtiges Glied in der Verkettung der verschiedenen Ansichten. Sie läfit sich als solches nur in ihrem ganzen Zusammenhange erkennen und muß daher aus $\mathrm{ihm}$ heraus interpretiert werden. Aus ihr lernen wir die Stellung kennen, die Eratosthenes zu dem Problem eingenommen hat.

Strabo handelt in dem 17. Buche zunächst ausfuhrlich über den Lauf des Nils, um dann die Frage nach seinem Steigen zu berühren p. 789 c. 5. Diese Frage sei durch den Augenschein gelöst worden, besonders durch die Reisen nach dem Zimtlande und die von Ptolemaeus Philadelphus auf die Elephantenjagd ausgesandten Gesellschaften. Die alten Könige hätten sich um solche Fragen nicht gekümmert, obwohl Sesostris ganz Aethiopien bis zum Zimtlande überzogen habe,

45) Diels, Seneca und Lucan S. 9. 
Kambyses bis Meroe vorgedrungen sei. Daher sei es wunderbar, daß von solchen Ansätzen aus keine deutliche Erkenntnis von den Regengüssen gewonnen sei. Ei үàp ăpa, fährt Strabo

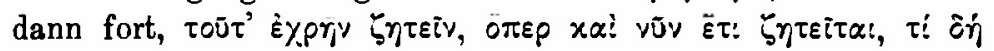

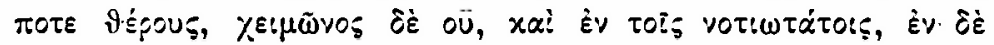

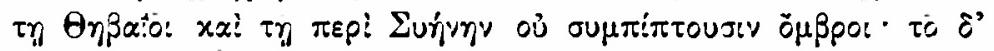

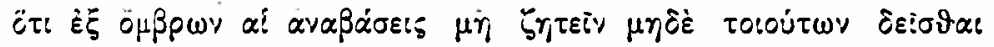

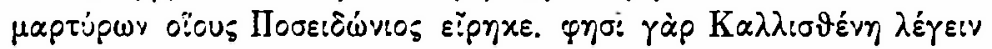

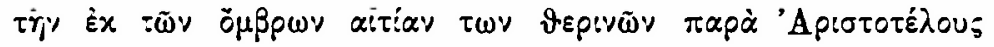

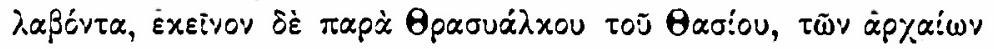

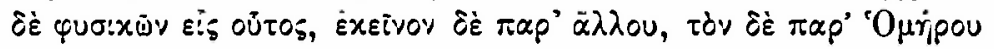

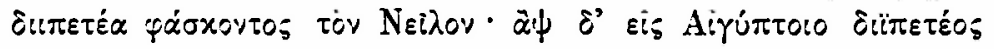
$\pi \tau \tau \alpha \mu c i c$.

Der verkürzte Satz $\varepsilon !$ үàp àpa dient nicht, wie es auf den ersten Blick scheint, zur Erklärung des unmittelbar Vorhergebenden und das Expry ist nicht die Zeit des Kambyses oder Sesostris. Denn in jener alten Zeit war ja eben, wie Strabo sagt, das, was man jetzt nicht mehr zu erforschen braucht, nicht erkannt worden. Der ganze Abschnitt über

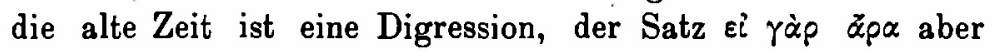
knüpft darüber hinaus unmittelbar an die Einleitung über die Entdeckungen unter den Ptolemaeern an. Da die sommerlichen Regengüsse in Aethiopien von Augenzeugen beobachtet worden sind, will Strabo sagen, und damit die Ursache der Nilanschwellungen festgestellt ist, so hätte man darnach, wenn man weiter forschen wollte, die noch ungelöste Frage untersuchen sollen, warum es im Sommer, aber nicht im Winter, und zwar auch nur im äußersten Süden, in der Thebais und um Syene aber uberhaupt nicht regne.

Posidonius wird also getadelt, nicht weil er eine falsche Ansicht ausgesprochen hat, denn in der Sache ist Strabo mit ihm vollkommen einverstanden, sondern dak er für diese Ansicht nicht die richtigen Zeugen angeführt hat. Es fehlte diesen Zeugen allen nach Strabo, das erhellt aus dem Zusammenhang, an der eigenen Erfahrung; sie waren samt und sonders Theoretiker und in Wahrheit sprach immer nur einer dem andern nach. So wird also Kallisthenes, der sich nach Iohannes Lydus gerade seiner eigenen Erfahrung rühmte, als 
Augenzeuge abgelehnt und es wird ausdrücklich bemerkt, dak er seine Ansicht von Aristoteles übernommen habe. Hat Posidonius das selbst gesagt, wie z. B. Rose meint ${ }^{46}$ ), so kann er nicht der Gewährsmann des Seneca gewesen sein, denn dann könnte er ja nicht von der Expedition des Kallisthenes nach Aethiopien gesprochen haben, auf die er sich nach Seneca gerade berufen hatte, um seine Selbständigkeit zu beweisen. Allein es ist nicht anzunehmen, dak Posidonius, wie es nach Strabo erscheint, immer ein Zeugnis aus dem andern ableitete und sie so schliekslich auf ein einziges reduzierte. Diese Darstellung ist vielleicht nur eine Kritik Strabos an Posidonius, während dieser der Meinung war, daks ein Zeugnis das andere stütze. Er braucht auch gar nicht alle von Strabo aufgeführten genannt zu haben, besonders nicht das des

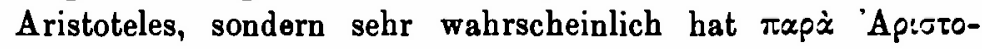

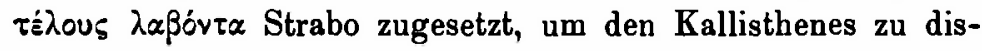
kreditieren.

Hatte Posidonius die Augenzeugen, die Strabo für maf̧gebend hielt, nicht aufgeführt, so war das vielleicht nicht deswegen unterblieben, weil er sie nicht kannte, sondern weil er nicht an sie glaubte. Auch Agatharchides, der in seinem Werke über das Rote Meer wohl von den Elephantenjagden unter dem zweiten Ptolemaeer gehandelt hatte ${ }^{47}$ ), berief sich zur Erklärung der Nilanschwellungen nicht auf die unter diesem Könige gemachten Entdeckungen, ebensowenig freilich auf Kallisthenes, und wenn er auch die Aussagen der umwohnenden Barbaren erwähnte, so war doch sein eigentliches Argument für die Annahme der sommerlichen Regengüsse in den Bergen Aethiopiens die Analogie der indischen Verhältnisse ${ }^{48}$ ).

Strabo tadelt den Posidonius bei einer andern Gelegenheit, daßs er das Zeugnis eines Kyzikeners Eudoxos für die Umschiffung Libyens unter Ptolemaeus Physcon als vollgültig anerkenne, dagegen die von Herodot und Heraclides Ponticus

16) Aristot. Pseudep. S. 241.

47) S. Photii bibliotheca cod. 250 p. 441 b $21 \mathrm{ff}$. ed. Bekker.

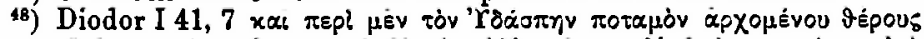

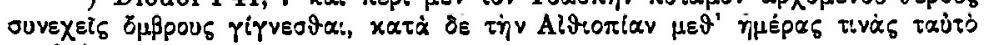
бuppaiveเv. 
angefübrten Umschiffungen als unbezeugt ablehne ${ }^{49}$ ). Strabos Kritik ist daher vielleicht auch hier in ähnlichem Sinne zu verstehen, daß̧ Posidonius fälschlich den Kallisthenes als Augenzeugen aufführe, die wahren Augenzeugen aber ignoriere.

$\mathrm{Ob}$ er seine Kenntnis von den Expeditionen unter Philadelphus aus den Reiseberichten selbst oder woher sonst geschöpft hat, sagt Strabo nicht. P. 769 beruft er sich dafür auf Artemidor. Daraus folgt natürlich nicht, dak derselbe auch an unserer Stelle zugrunde liegt, wohl aber, dak Strabo schwerlich seine Kenntnis aus erster Hand hat. Und in der Tat läet sich ihre literarische Basis noch deutlich erkennen. Strabo hängt auch in diesem Abschnitt, ebenso wie im Anfang des Buches, wo er es ausdrücklich sagt, von Eratosthenes ab, wenn auch vielleicht nicht ganz so sklavisch, wie Rose meinte ${ }^{50}$ ). Immerhin ist der Anschluf auch im Ausdruck eng genug.

Aus dem Kommentar des Proclus zu Timaeus p. 22 E ersehen wir nämlich, daÉ schon Eratosthenes sich zu der von Strabo vertretenen Ansicht uber das Steigen des Nils bekannte und mit Berufung auf das Urteil von Augenzeugen erklärt hatte, man brauche dieser Frage nicht mehr nachzugehen. $\mathrm{Ja}$, auch er hatte von Aristoteles gesprochen und gesagt, seine Ansicht sei durch jene Augenzeugen bestätigt worden: 'Eparoo-

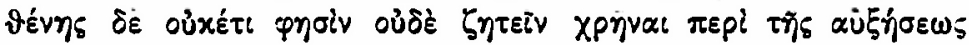

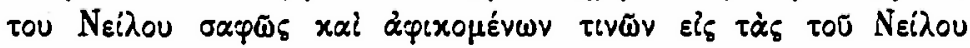

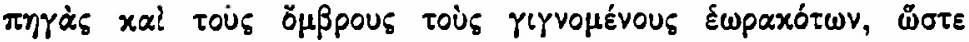

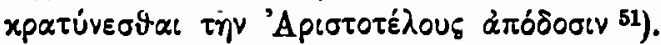

Durch diese Notiz wird der oben bei Strabo festgestellte Zusammenhang bestätigt, da $\hat{B}$ man sich deswegen mit der Frage nach den Nilanschwellungen nicht mehr zu beschäftigen brauche, weil die Ursache durch den Augenschein klargestellt sei. Strabo hängt also auch im Anfang des Kapitels von Eratosthenes ab und dadurch wird wiederum die Notiz bei Proclus ergänzt, indem wir nun erkennen, dás Eratosthenes an die Entdeckungen unter Ptolemaeus Philadelphus gedacht

48) II p. 98.

50) Aristotelis opera, ed. Acad. Bor. V 1520 b 13, Anm, und Aristoteles pseudepigraph. p. 716.

51) Proclus in Timaeum, ed. Diehl I 121. 
hatte. Offenbar stammt aber auch die Digression bei Strabo über Sesostris und Kambyses aus Eratosthenes. Denn im 16. Buch p. 769 berichtet Strabo unter ausdrücklicher Angabe seiner Quelle nach Eratosthenes von demselben Zuge des Sesostris. Charakteristisch ist, wie Strabo sich an unserer Stelle, wo er die Gedanken des Eratosthenes sich zu eigen. gemacht hat, sehr viel sicherer spricht als Eratosthenes selber es getan hatte. Denn während Strabo hier sagt, man zeige. noch jetzt die von Sesostris zum Andenken an seinen Feldzug errichtete Säule und Inschrift, hatte Eratosthenes, wie wir p. 769 sehen, dies vorsichtig nur als Aussage anderer berichtet. Nimmt man die Notiz des Proclus für sich allein, so hat man den Eindruck, als habe Eratosthenes ohne Polemik nur die Tatsachen oder das, was er dafür hielt, dargelegt.

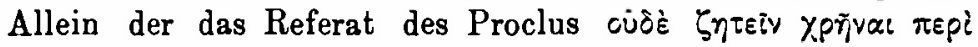

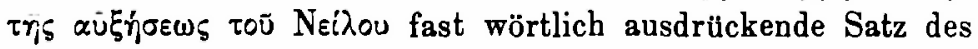

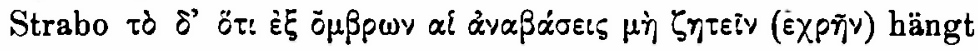
mit seiner Polemik gegen Posidonius unmittelbar zusammen und hierbei fällt der Infinitiv $\delta \varepsilon i \sigma \vartheta \alpha \iota$ auf, der geradezu falsch

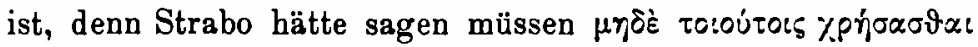

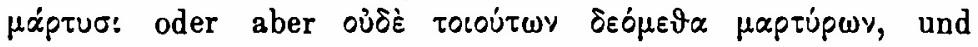
$\delta \in \tilde{\tau} \sigma \vartheta^{\prime} \alpha$ ist eigentlich nur zu verstehen, wenn man es von Ex$\times r_{i} v$ unabhängig macht und als Infinitiv der indirekten Rede faßst. Vielleicht erklärt sich diese Inkorrektheit aus der starken gedanklichen Abhängigkeit Strabos von Eratosthenes. Es muk ferner aufallen, daß Homer von Strabo auf eine Stufe mit den andern Alten gestellt wird, die, wie es im Anfang des Kapitels heißjt, mehr nach Gutdünken als nach wirklichem Wissen urteilen, was nicht nur der allgemeinen Auffassung Strabos von dem Dichter widerspricht, sondern insbesondere der Meinung, die er von seinem Wissen um den Nil und Aethiopien hat. Denn er verteidigt p. 32 Homers Einteilung der Aethiopen, die er, anders als üblich, von der Teilung durch den Nil versteht, und meint, daß̧ Homer, wie von den Mündungen des Nils, so von seinen Anschwellungen Bescheid gewukt habe ${ }^{52}$ ). Diese Verteidigungen Homers sind aber speziell gegen Eratosthenes gerichtet.

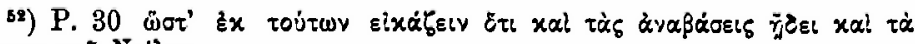
otópata toú Nsihov. 
Der Tadel gegen Homer p. 790 ist also ein weiteres Zeichen, dab Strabo seine Argumente gegen Posidonius auch in einzelnen von Eratosthenes entlehnt hat. Daß ferner Eratosthenes auch den Aristoteles erwähnte und ihm die Richtigkeit seiner Ansicht ausdrücklich bezengte, sehen wir aus Proclus.

Hiernach ist es im höchsten Grade wahrscheinlich, dafi Eratosthenes auch in der Polemik Strabo voraufgegangen ist. Diese kann gegen Kallisthenes direkt, sie kann aber auch gegen jemand gerichtet gewesen sein, der sich auf Kallisthenes stützte. In diesem Falle würde Strabo die Kritik des Eratosthenes von einem Unbekannten einfach auf Posidonius, der über Eratosthenes hinüber wieder zu dem Glauben an Kallisthenes zurückgekehrt war, übertragen haben. Der flüchtigen kompilatorischen Art, die Strabo an dieser Stelle verrät, würde eine solche Annahme am meisten entsprechen ${ }^{53}$ ). Hierbei würde allerdings nicht mit Notwendigkeit vorauszusetzen sein, daß3 Eratosthenes die Meinung bekämpfte, als wenn Kallisthenes selbst ein Augenzeuge der Regengüsse in Aethiopien gewesen sei, sondern vielleicht bestritt er nur, daß es zur Zeit des Kallisthenes überhaupt schon Erfahrungen darüber gegeben habe.

Das Hauptargument des Eratosthenes gegen diese Behauptung ist offenbar die Annahme gewesen, die Ansicht des Kallisthenes sei im Grunde dieselbe wie die des Aristoteles. Wir haben zu fragen, woher Eratosthenes diese kannte und was es mit ihr überhaupt für eine Bewandtnis hatte.

In den erhaltenen Schriften des Aristoteles findet sich nirgendwo eine ausdrückliche Erklärung der Nilanschwellungen. Aber in den Meteorologica wird die Tatsache der heftigen Regengüsse in Arabien und Aethiopien während des Sommers

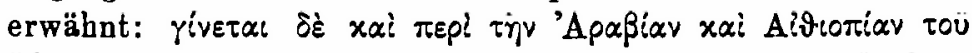

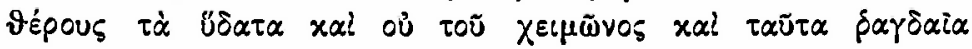
(I 12,19). F'reilich wird diese Tatsache nicht ausdrücklich

53) Rose geht so weit, dafs er annimmt, Strabo habe im folgenden Eratosthenes mechanisch ausgeschrieben und seine angeblichen Zeit-

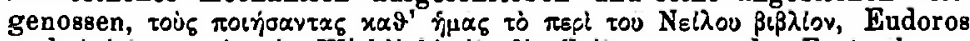
und Ariston, seien in Wirklichkeit die Zeitgenossen des Eratosthenes gewesen. 
mit dem Steigen des Nils in Verbindung gebracht und es wird für sie eine ganz andere Erklärung als bei Kallisthenes gegeben durch die Annahme einer eigentümlichen Wechsel-

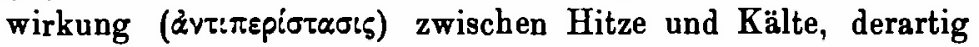
daE die von der Hitze eingeschlossene Wolke abgekühlt und in Wasser aufgelöst werde, wobei aber von der von den Physikern so lebhaft diskutierten Ursache der Wolkenbildung in Aethiopien weiter keine Rede ist.

Kann Eratosthenes diese Stelle vor Augen gehabt haben? Daß die Regengüsse nicht ausdrücklich als Ursache der Nilanschwellung bezeichnet werden, will nicht viel besagen, da dieser Zusammenhang sich von selbst ergibt. $\mathbf{Z u}$ größeren Bedenken gibt die Verschiedenheit in der Erklärung der Regengüsse selbst Veranlassung. Allein man muß zwischen der Ursache der Regengüsse und der Ursache der Nilanschwellung unterscheiden und sowohl aus Strabo wie aus Proclus mú man schlieken, dak es Eratosthenes lediglich auf die letztere angekommen ist. Durch den Augenschein liek sich ja auch nur diese feststellen, während die erstere immer im Bereiche der Theorie blieb. Wenn also Eratosthenes mit Befriedigung konstatierte, daß̧ die Regengüsse nun tatsächlich in Aethiopien beobachtet seien, so konnte er sehr wohl sagen, die Behauptung des Aristoteles in den Meteorologica sei nun bestätigt worden. Und tatsächlich läbt ihn Proclus doch nichts weiter sagen.

Es hat nun aber unter dem Namen des Aristoteles ein

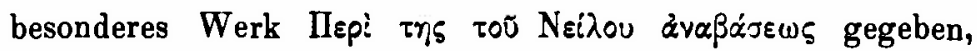
und es ist noch jetzt ein kurzer Abrik in einer mittelalterlichen lateinischen Uebersetzung unter dem Titel Liber Aristotilis de inundacione Nili erhalten ${ }^{54}$ ).

Von den verschiedenen Ansichten über die Frage, die in diesem Abriß besprochen werden, ist die letzte dieselbe, die von den Doxographen dem Kallisthenes zugeschrieben wird. Sie wird als die einzig richtige empfohlen und zwar ebendeswegen, weil sie den Augenschein für sich habe:

54) Veröffentlicht von V. Rose, Aristoteles Pseudepigraphus, S. $633-639$. 
Nunc autem relinquetur sola causa dictorum. Hanc causam dicendum, propter quod iam non problema videtur esse: in sensum enimvenit, quemadmodum per se videntes facti a visis 〈dicunt〉. Videntur enim aque facte per tempora hec a cane usque ad arcturum multe et habundanter, hyeme autem nulle, et fuctus nutriuntur, cum crescunt in ipsis. Et propter hoc simul annualibus advenit fuvius: isti enim nebulas maxime ferunt in regionem 〈meridionalem> et quicunque alii venti fiunt estivales ante hos. Quibus offendentibus ad montes defluunt aque ad stagna per que Nilus fluit.

Diese Schrift ist als aristotelisch auch von dem anonymen Verfasser der von Photius gelesenen Biographie des Pythagoras zitiert worden ${ }^{55}$ ). Damit verknüpfte aber dieser Verfasser die Bemerkung, Aristoteles habe diese Ansicht auf Grund der Erhebungen ausgesprochen, die Alexander der Große an Ort und Stelle habe anstellen lassen. Der Biograph muß die Schrift noch in einem vollständigeren Zustande als der mittelalterliche Uebersetzer gekannt haben, denn er beginnt mit einer Erklärung der Entstehung der Passatwinde, die in der lateinischen Uebersetzung fehlt, aber derselben Quelle entstammt. Im unmittelbaren Anschluß daran fährt er fort:

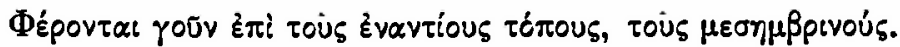

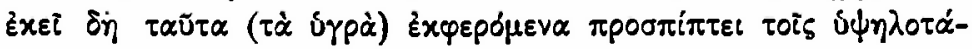

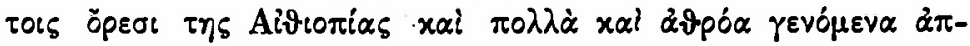

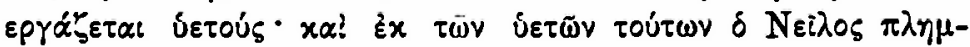

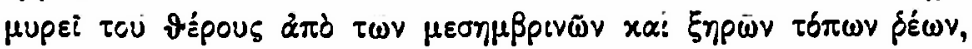

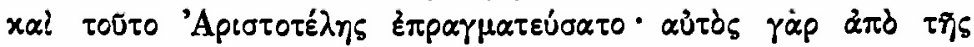

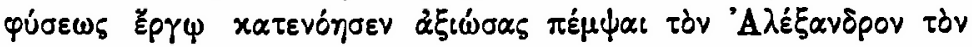

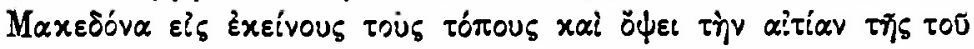

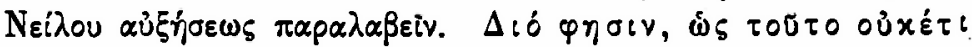

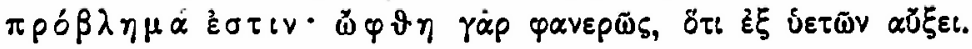

An den ersten Satz des eben zitierten Abschnittes der lateinischen Uebersetzung klingt nun auch der Anfang des von Strabo aus Eratosthenes entlehnten Kapitels an: $O\{\mu \dot{\varepsilon} \nu$

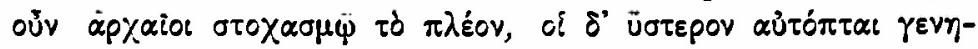

55) Cod. 249 g. ్. p. 441 a $34 \mathrm{ff}$. 


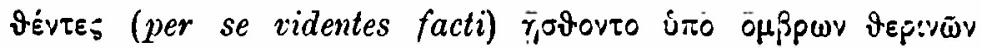

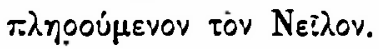

Müssen wir daraus scnließen, daß Eratosthenes die Schrift über das Steigen des Nils gekannt hat? Die Uebereinstimmung des Ausdrucks ist in der Tat auffallend, und die Annahme des umgekehrten Verhältnisses ist durch die Beschaffenheit der Schrift ausgeschlossen. Aber mag Eratosthenes die Schrift gekannt haben oder nicht, so kann er sie sicher nicht für aristotelisch gehalten haben. Denn die Autopsie war ja nach seiner Mleinung erst unter Philadelphus gewonnen worden, und wie hätte er sagen können, durch die Entdeckung unter diesem König wäre die Ansicht des Aristoteles bestätigt worden, wenn dieser selbst sie aus den Erfahrungen seiner eigenen Zeit abgeleitet hätte? Wenn also die Uebereinstimmung des Ausdrucks nicht durch die Sache herbeigeführt ist, so mußs Eratosthenes entweder die Entstehung der Schrift in die Zeit des Philadelphus gesetzt haben, oder aber, wenn er wußste, daßs sie älter war, ihre Behauptung haben rektifizieren wollen, indem er sie wörtlich in diese Zeit übertrug.

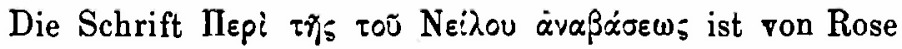
aus andern Gründen für unecht erklärt und dem Theophrast zugesprochen worden, und Diels, der zwar Roses Gründe für schwach erklärt, nimmt gleichwohl seine Ansicht an. Dagegen hat Partsch in den Abhandlungen der Sächs. Ges. d. W. 1909 S. $551 \mathrm{ff}$. die Schrift für Aristoteles in Anspruch genommen und $W$. Capelle hat sich ihm in seinem schönen Aufsatz über die Nilschwelle in den N. Jahrbüchern f. d. kl. Altertum 1914 S. $331 \mathrm{ff}$. angeschlossen. Wir müssen die Frage von neuem prüfen.

Zunächst stimmt mit Aristoteles nicht die Erklärung, die der Biograph des Pythagoras nach der Schrift über den Nil von der Entstehung der Passatwinde gibt. Die Passatwinde entwickeln sich nach Aristoteles ${ }^{56}$ ) wie die Winde überhaupt aus trockener Ausdünstung, denn der Wind ist nach ihm eine gewisse Menge trockner Ausdünstung aus der Erde, die sich

s8) Meteorol. II 5,6 . 
um die Erde bewegt ${ }^{57}$ ). Bei dem Biographen aber scheint die von Aristoteles bestrittene Definition, daß Wind bewegte Luft sei ${ }^{58}$, zugrunde zu liegen, wenn er sagt: $\delta \eta_{j} \lambda \cos _{5} \mu \in \tau-$

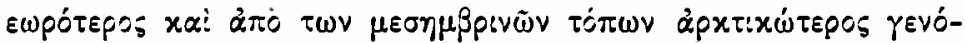

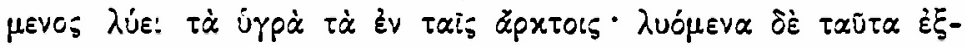

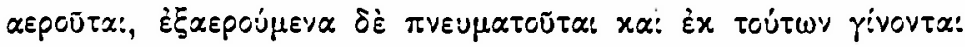

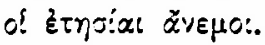

Noch stärkere Zweifel an dem aristotelischen Ursprunge der Schrift über das Steigen des Nils erwecken die vermeintlichen Anführungen der Commentatoren des Aristoieles aus ihr. Während Aristoteles in den Meteorologica die Abkuthlung für die einzige Ursache des Regens iberhaupt und speziell in Aethiopien erklärt, bemerkt der Grammatiker Iohannes zu Arist. De gen. et corr. I, 5 mit Berufung auf Aristoteles, daß daneben auch Stoß 3 und Druck als Ursache anzunehmen

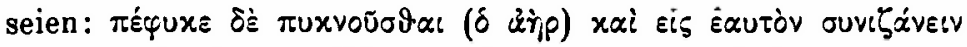

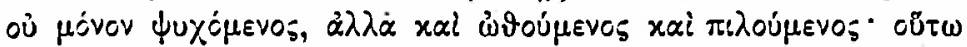

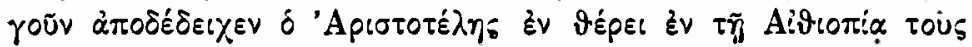

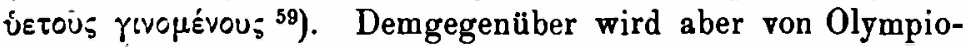
dor in den Erläuterungen zu den Meteorologica diese zweite Ansicht gerade der des Aristoteles als die des Theophrast

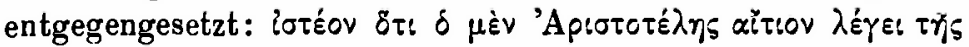

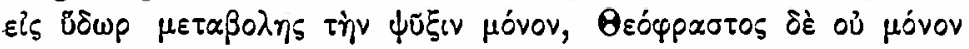

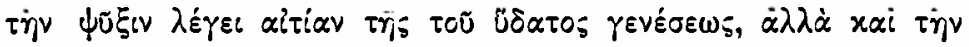

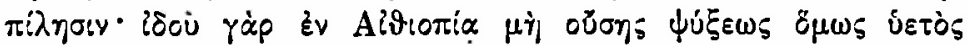

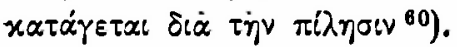

Auf ein zweites Zeugnis neben dem des Iohannes, nämlich des Alexander in dem Commentar eben zu den Meteorologica p. 349 a 5 hat Diels in den Doxographi S. 226 A. 2 hingewiesen. Nachdem Alexander die Ansicht des Aristoteles über die Entstehung der Regengüsse in Aethiopien auf dem Wege der Abkühlung festgestellt hat, sagt er, es möchte dagegen der Einwand erhoben werden, daß die Trockenheit des Sommers in Aethiopien eine Wolkenbildung ausschlösse. Diesen Einwand beantwortet er so: $\bar{\eta} \alpha\lfloor\mu \varepsilon \dot{\varepsilon} \nu \alpha \dot{\nu} \alpha \vartheta \cup-$

57) 4,25 59) 4,7 .

59) Nach Rose Áristot. pseudep. S. 241.

${ }^{\circ 0)}$ Olymp. zu Axist. Met. I 9, 1 in Aristot. Meteor. ed. Ideler I 222.

Pbilologus LXXIV (N. F. XXVIII), 1. 


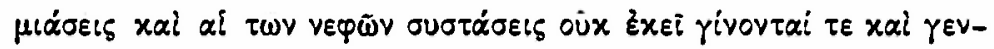

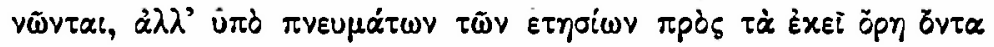

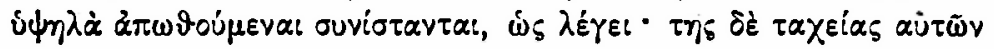

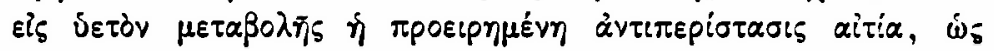

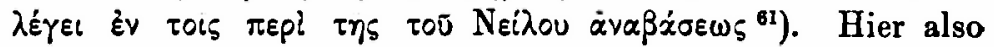
wird die Schrift des Aristoteles, wie es scheint, selbst angeführt. Allein wir dürfen über die Stelle nicht rasch hinweggehen, denn sie enthält einige Schwierigkeiten.

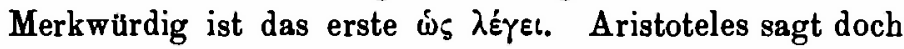
das Angeführte in den Meteorologica eben nicht, sondern es wird zur Erklärung dessen, was er dort sagt, irgendwober

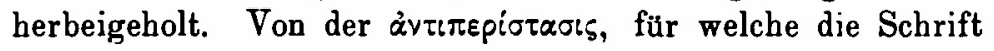
über das Steigen des Nils zitiert wird, ist aber gerade in diesem Kapitel der Meteorologica ausführlich die Rede und sie wird eben hier als Ursache der Abkühlung, durch welche die Verwandlung in den Regen vor sich geht, bezeichnet. Die Ueberlieferung kann also nicht in Ordnung sein; zu dem ersten $\dot{\omega} \varsigma \lambda \hat{\gamma}^{\prime} \varepsilon \iota$ fehlt das Subjekt und das zweite mit seiner näheren Bestimmung steht nicht am richtigen Orte. Diese gehört vielmehr zu dem ersten $\omega \varsigma \lambda \varepsilon$ $\lambda \varepsilon \varepsilon$ und als Subjekt ist

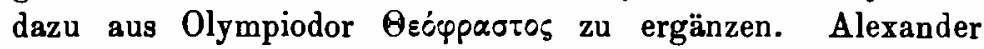
sucht also zwischen Theophrast und A ristoteles zu vermitteln. Er nimmt von jenem die Hypothese, das die Wolken ron den Passatwinden nach Aethiopien getrieben werden, behält aber die Erklärung des Aristoteles bei, daß ihre Umwandlung

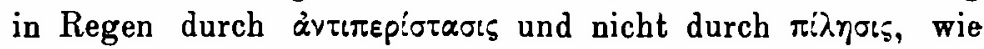
Theophrast wollte, herbeigeführt werde.

Olympiodor fährt an der oben zitierten Stelle fort: $\varphi \eta \sigma i$

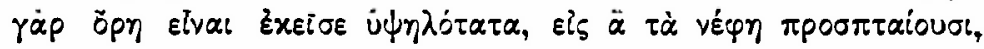

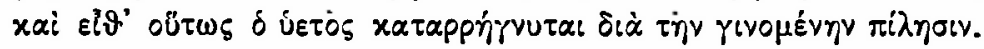

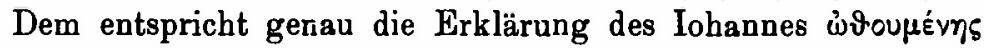

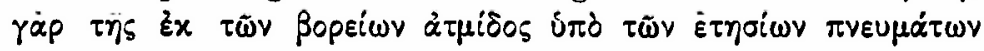

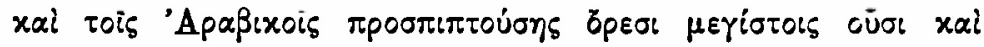

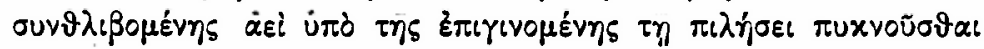

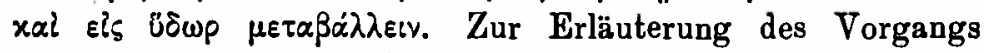
fügte Theophrast eine Beobachtung aus den Bädern hinzu,

61) Alexander in Meteor. ed. Hayduck p. 53, $11 \mathrm{ff}$. 
die bei beiden in der Sache ubereinstimmend angegeben wird. Die an die Berge anstoßenden Wolken kämen in derselben Weise als Wasser herunter wie in den Bädern die an der Decke emporsteigenden Dämpfe, welche sich dort verdichteten und durch den Gegendruck der Decke ohne Abkühlung zu Wasser würden.

Die bei Alexander behandelte Frage, wie trotz der Trockenheit des Sommers sich die Regenbildung in Aethiopien vollziehen könne, wird bei Olympiodor an einer anderen Stelle gleichfalls berührt und hier die Erklärung Theophrasts noch

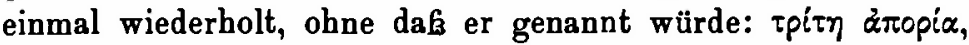

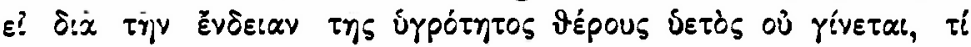

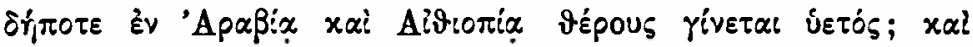

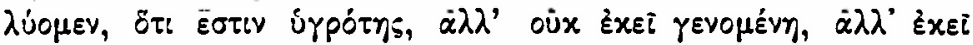

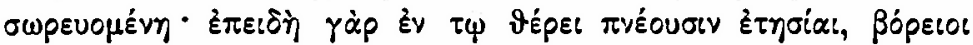

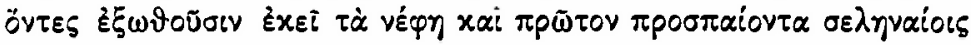

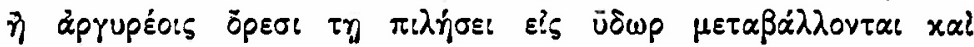
$\left.x \alpha \tau \alpha^{\prime} \gamma \varepsilon \tau \alpha: \tilde{v} \delta \omega \rho^{B 2}\right)$.

Es ist dieselbe Ansicht, die wir am Schluk der Schrift De inundatione Nili und in Uebereinstimmung damit bei dem Biographen des Pythagoras finden.

Daß̧ sie tatsächlich, wie aus Olympiodor hervorgeht, von Theophrast stammt und es keine besondere Schrift des Aristoteles uber das Steigen des Nils gegeben hat, dürfte nun nicht mehr zweifelhaft sein. Damit ist indessen nicht gesagt, dak Theophrast der Verfasser der Schrift war, die uns im Auszug in der lateinischen Uebersetzung erhalten ist. In dem Verzeichnis der Schriften des Theophrast bei Laertius Diogenes wird keine solche Schrift genannt, und was die Commentatoren des Aristoteles aus Theophrast anführen, könnte sehr wohl in einer seiner vielen physikalischen Schriften gestanden haben. Auch der Hinweis Alexanders auf $\tau \dot{\alpha} \pi \varepsilon \rho ?$ in̆ $\dot{\alpha} \vee \alpha \beta \alpha \dot{\alpha} \sigma \varepsilon \omega s$ scheint mir nicht notwendig auf eine besondere Schrift zu deuten.

Mit der Ansicht Theophrasts deckt sich aber auch, was bei dem Anonymus Florentinus als Ansicht des Kallisthenes angeführt ist(s. o.S. 17. Die Uebereinstimmung ist z. T. auch im Wort(2) Ideler S. 233. 


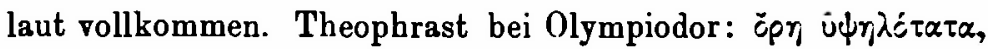

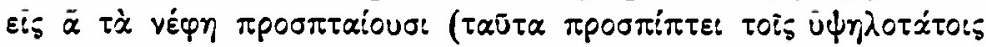

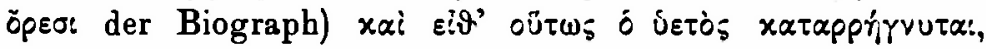

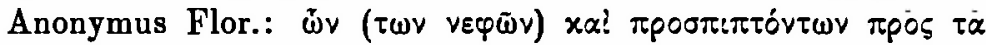

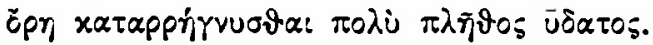

Kallisthenes wird sich also von Theophrast haben beraten lassen, als er den Abschnitt uber das Steigen des Nils schrieb, was bei dem engen Verhältnis der beiden nicht zu verwundern ist.

Wir erfahren aber von dem Anonymus Florentinus, dak Kallisthenes nicht nur seine eigene Ansicht über die Nilanschwellungen ausgesprochen, sondern damit auch eine Kritik

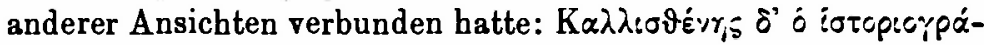

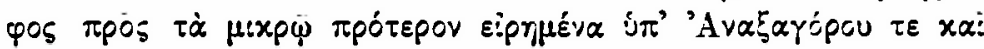

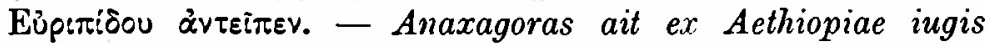
solutas nives ad Nilum usque decurrere. In eadem opinione omnis vetustas fuit. Hoc Aeschylus, Sophocles, Euripides tradunt. Sed falsum esse pluribus argumentis patet, so beginnt Seneca seine Auseinandersetzungen über die Ursachen der Nilanschwellungen und mit besonderem Nachdruck wird die Ansicht des Anaxagoras auch in der Schrift De inundatione bekämpft. Aber schwerlich ist die Angabe des Anonymus so genau, daßs wir zu der Annahme gezwungen wären, Kallisthenes habe sich auf die Widerlegung dieser einen Ansicht beschränkt. Von all den in der Schrift De inundatione aufgeführten Ansichten aber ist keine, die nicht auch bei einem der andern Doxographen verzeichnet wäre. Zwar kommt die Aufzählung der bei Seneca-Iohannes Lydus an Vollständigkeit nicht gleich, dabei ist aber zu bedenken, daß die Schrift uns nicht in ihrer ursprünglichen Gestalt vorliegt.

Bezeichnend ist die Uebereinstimmung ihres Anfangs mit dem des entsprechenden Abschnittes der Naturales Quaestiones des Seneca: Propter quid aliis fuminibus in hyeme quidem augmentatis, in estate autem multo factis minoribus, solus eorum qui in mare fuunt multum estate excedit? - N. Q. IV a 2, 17: Sed nunc ad inspiciendas causas, propter quas aestate Nilus crescat, accedam et ab antiquissimis incipiam.

Die Zeit der Schrift oder, genauer gesprochen, der Quelle 
der Schrift läßt sich annäherungsweise bestimmen: sie muß nach dem Aufstande Aegyptens unter Artaxerxes III. und vor oder doch nicht allzulange nach dem Feldzug Alexanders in Indien entstanden sein.

Von Artaxerxes Ochus wird eine Anekdote erzählt, die in bemerkenswerter Weise an die Ansicht über den Indus erinnert, die Nearch Alexander zuschrieb (S. 18). Als Artaxerxes gegen Aegypten zu Felde ziehen mufite, wollte er einen indischen Fluk, dessen Name, wie es scheint, in unserer Schrift ausgefallen ist, von seinem Laufe ablenken, denn er hatte gehört, daß er Krokodile habe wie der Nil, und hielt ihn daher für denselben. Nachdem er dann belehrt war, daf der Fluß in das rote Meer fliefe, stand er von seinem Vorhaben ab. Er hörte dann aber von einem andern Flusse, der von dem Berge Aletas käme, aus dem der Indus entspringe. Dieser ${ }^{63}$ ) habe Krokodile und flösse auken um das rote Meer herum, sei es nun, dak dies die Wahrheit war, sei es daß es eine Lüge war, wie es in der Schrift heibt. Der König nahm nun seinen alten Plan wieder auf, aber man sagte ihm, daß er damit einen größeren Strich vernichte als er bekäme, wenn er die Aegypter bezwänge (p. 635, 1 ff.).

Es ist hier offenbar noch mit der Möglichkeit gerechnet, das der Nil in Asien entspränge und mit dem Indus identisch sei, wenn auch das Zutrauen zu dieser Meinung gering ist. Aber wenn die unter Alexander gemachten Erfahrungen bekannt gewesen wären, so wäre die phantastische Beschreibung von dem Lauf des Indus gewiß energisch zurückgewiesen worden.

Damit stimmt es, dak der Verfasser da, wo er seine eigene Meinung über die Ursachen der Nilanschwellung ausspricht, die Frage nach den Quellen des Nils, die öfters, insbesondere auch von Eratosthenes, damit verquickt wurde, völlig unerörtert läßt und nicht behauptet, daßs der Nil in den Bergen Aethiopiens entspränge. Er läßt vielmehr die in Aethiopien

(3) Quia fluvius alter esset ad illas partes Indie fiuens ex monte Aleto, ex quo quidem Indus. Hunc autem dicebant habere crocodillos etc. Es ist doch wohl gemeint, daß der Indus aus dem ungenannten Fluk entispringe, im weiteren aber von dem Indus die Rede sei. 
niedergehenden Wassermengen in die Sümpfe sich ergiefen, durch die der Nil flieft. Woher aber dieser selbst kommt, bleibt dabei ganz außer Frage.

Eine Kleinigkeit verdient vielleicht noch Erwähnung. An vorletzter Stelle wird, ohne Namensnennung, die Ansicht des Oenopides ron Chios erörtert, daßs der Nil im Winter eintrockne. Dabei wird eine Beobachtung aus der Heimat des Kallisthenes erwähnt, daß es im Gebiet von Olynth Brunnen gebe, die im Sommer ibren höchsten Wasserstand hätten.

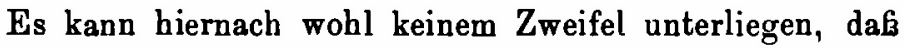
die Schrift De inundatione Nili auf Kallisthenes und zwar, wie man aus Iohannes Lydus schliefen muk, das vierte Buch seiner Hellenica zurückgeht.

Dieses ist also die Grundlage der uns erbaltenen doxographischen Abrisse über das Steigen des Nils gewesen, und es ist nun klar, wie es kommt, dak darin allein von der Ansicht des Kallisthenes genau der Fundort angegeben ist.

Wir werden kaum fehlgehen, wenn wir annehmen, daks Nearch die Ansicht über den Indus, die er Alezander beilegt, Kallisthenes entnommen hat und er selber davon beherrscht war, bis Alexander und seine Begleiter durch die Erfahrung eines besseren belehrt wurden. Man lernte zugleich die sommerlichen Anschwellungen der indischen Flüsse kennen, verglich die analogen Erscheinungen in Aegypten und setzte in beiden Fällen die gleichen Ursachen, ohne die Einwendungen gegen die Annahme einer Schneeschmelze in Aegypten zu beachten ${ }^{64}$ ).

Es ist möglich, aber nicht wahrscheinlich, daß Kallisthenes sich eingehender Uber die Augenzeugen der sommerlichen Regengüsse in Aethiopien geäufert hat, als es in der Schrift De inundatione geschieht. Gern werden wir glauben, daß̧ zu seiner Zeit mehr oder minder beglaubigte Berichte von Reisenden darüber nach Athen gekommen waren, die im Peripatos begierig aufgegriffen wurden, zur Zeit des Eratosthenes aber und wohl auch schon des Philadelphus verschollen waren. Begreiflich aber ist es, daß̧ man sich später darüber Gedanken machte und unter dem Eindruck der Ueberlieferung,

64) Strabo XV p. 691-693. 
daG Kallisthenes Alexander auf seinen Zügen begleitet habe, der Glaube aufkam, Kallisthenes sei selbst in Aethiopien gewesen.

Was Posidonius bewogen hat, dem Kallisthenes eine so große Autorität beizulegen, kann nur die Meinung gewesen sein, dak er der schon vor ihm, von Thrasyalkes, wie Posidonius meinte, aufgestellten Theorie eine empirische Grundlage gegeben habe. Wenn wir Posidonius auch nicht die falsche Behauptung zutrauen können, Kallisthenes habe selbst ausgesagt, er sei in Aethiopien gewesen, so werden wir es doch begreiflich finden, daß̧ er die herrschende Meinung, Kallisthenes sei mit Alexander in Aegypten gewesen, mit seiner Aussage über die Erfahrung der Augenzeugen in Aethiopien kombinierte, wenn er nicht eine solche Kombination bereits vorfand. Vielleicht hat Seneca noch von einer bloßen Vermutung gesprochen und erst Iohannes Lydus sie in eine unmittelbare Aussage des Kallisthenes selbst umgesetzt, jedenfalls aber hat nicht Seneca die Vermutung aufgestellt, sondern sie bei Posidonius vorgefunden, da wir über die von Alexander dem Groken nach Aethiopien entsandte Expedition eine von Seneca unabhängige doppelte Ueberlieferung besitzen.

Der Biograph des Pythagoras knüpft sie unmittelbar an die Aeuferungen des Kallisthenes an, aber er weik nicht mehr, daß es die Aeußerungen des Kallisthenes sind, sondern hält sie für aristotelisch. Diese Meinung muß auf dem Wege einer kürzeren oder längeren Vermittlung daraus entstanden sein, daB man aus den Beziehungen des Kallisthenes zu Aristoteles den Schluß zog, Kallisthenes habe auf seine Veranlassung bei Alexander die Schritte bewirkt, die zu der von ihm erwähnten Entdeckung führten. Auch hier lag die Voraussetzung zugrunde, daE Kallisthenes mit Alexander in Aegypten gewesen sei. Dak die Hellenica bereits vor Alexanders Zug nach Aegypten abgeschlossen waren, übersah man dabei.

Bei Lucan und vielleicht von Lucan ist das Ergebnis dieser Expedition in einen Mißerfolg umgewandelt, indem zugleich als ihr eigentliches Ziel die Entdeckung der Nilquellen bezeichnet wurde. 
Es wird also durch die Nachricht des Iohannes Lydus nicht das mindeste für die Anwesenheit des Kallisthenes in Aegypten bewiesen und die Frage nach der Echtheit des ihm zugeschriebenen Werkes über Alexander bleibt davon gänzlich unberührt.

Das Werk war, wie bereits bemerkt, schon dem Timaeus unter dem Namen des Kallisthenes bekannt. Wir müssen die Frage wenigstens stellen, ob auch die altern Historiographen Alexanders selbst irgend welche Kenntnis davon zeigen. $\mathrm{Da}_{\mathrm{a}}$ für kommt besonders diejenige Partie der Schrift in Betracht, uber die wir durch die Kritik des Polybius am genausten unterrichtet sind, die Schilderung der Schlacht bei Issos ${ }^{65}$ ).

Die Darstellung war ebenso wie die der Schlacht bei Gaugamela, die Plutarch benutzt hat ${ }^{66}$ ), so angelegt, daf das Interesse des Lesers auf die Person des Königs konzentriert wurde. Bei Issos wie bei Gaugamela ging dieser hiernach darauf aus, sobald wie möglich an den Perserkönig heranzukommen, um ihn im persönlichen Kampfe zu überwinden. Dabei fehlte es keineswegs an detaillierten Angaben über die Zahl der verschiedenen Truppengattungen und die Beschaffenheit des Terrains, ohne daß jedoch dadurch Anschaulichkeit und Klarheit erreicht wurde.

Ich habe nicht die mindeste Berechtigung, über die militärische Bedeutung der verschiedenen Berichte und ihren Wert für die so eifrig diskutierte Frage nach der Oertlichkeit der Schlacht zu urteilen, aber es läßt sich vielleicht auch ohne dies erkennen, dafs die von Polybios beanstandete Darstellung die bei Arrian erbaltene des Ptolemaeus und Aristobulos zur Voraussetzung hat.

Wenn Polybios Klarheit bei Kallisthenes vermifit, so ist er freilich selbst in seinem Berichte über ihn nicht völlig klar. Darius und seine Feldherrn, sagt $\mathrm{er}^{67}$ ), hätten nach Kallisthenes beschlossen, ihre ursprüngliche Schlachtordnung wieder einzunehmen und dabei den Flus Pinaros zur Deckung zu benutzen. Darauf hätten sie die Reiterei am Meere aufgestellt, die Söldner daneben unmittelbar am Fluk, daran an-
(5) Polyb. XII $17 \mathrm{ff}$.
o8) Alex. c. 33.
67) c. 17,6 . 
schliekend die Peltasten bis an die Berge. Diese Schilderung wird von Polybius bemängelt, denn es sei nicht zu begreifen, wie Darius diese Massen vor der Phalanx hätte aufstellen können, da der Fluk doch unmittelbar an der Aufstellung vorbeigeflossen sei ${ }^{68}$ ). Dieser Einwurf ist überraschend und völlig unrerständlich, da man nichts davon erfährt, daß̧ Kallisthenes gesagt hatte, diese Truppen seien vor der eigentlichen Schlachtreibe aufgestellt gewesen, und man fragt sich vergeblich, aus was für Truppen denn die Schlachtreihe selbst bestanden habe, da es nach dem weiteren Bericht eben die Reiter und Söldner sind, die die Schlacht schlagen und bei dem Nachweis, daG die von Kallisthenes angegebenen räumlichen Maasse mit der von ihm genannten Truppenzahl nicht stimmten, auf persischer Seite nur die Reiter und Söldner berücksichtigt werden. Diese Unklarbeit kann nicht allein Schuld des Kallisthenes sein. Wenn Polybius, nachdem er über die Aufstellung der Reiter, Söldner und Peltasten gesprochen hat, fragt: $\pi \bar{\omega} \varsigma \delta \grave{\varepsilon}$

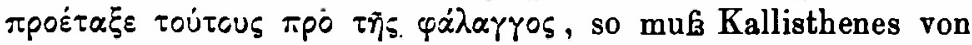
einer Bewegung eben dieser Truppen oder der Reiter und Söldner, denn nur von deren Zahl ist nachber die Rede, nach der ersten Aufstellung gesprochen haben, er kann dabei aber den Fluß nicht erwähnt haben, da Polybius diesen als das Hindernis der von Kallisthenes angegebenen Aufstellung bezeichnet. Bei Arrian ist das Manöver, das Kallisthenes offenbar sehr ungeschickt und undeutlich geschildert hatte, ganz klar. Als Darius der Anmarsch Alexanders gemeldet wurde, heifit es dort ${ }^{69}$ ), schickte er 30000 Reiter und 20000 Leichtbewaffnete über den Fluk, um den Rest seiner Streitmacht, unter ihnen die 30000 Söldner (die Zahlen der Reiter und Söldner sind dieselben bei Kallisthenes), in Ruhe aufzustellen. Als dies geschehen, rief er dann die Reiter - von den Leichtbewaffneten ist nicht mehr die Rede - wieder über den Fluf zurück und stellte sie auf dem rechten Flügel am Meere auf ${ }^{70}$ ). Dem rhetorischen Charakter der Darstellung des Kallisthenes entsprach es, dak er den Fluk, dessen schroffe und schwer zu erklimmenden Uferböhen er vorher lebhaft geschildert hatte, im Laufe der Erzählung völlig aus den Augen verlor, indem
68) $17,7$.
69) II 8,5 .
70) 8,10 . 
er der Schwierigkeiten, die dieser dem Angriff der Makedonen bot, nicht im mindesten gedachte ${ }^{71}$ ), wie das freilich ebensowenig Diodor und Curtius tun.

Ganz anders liegt die Sache bei demjenigen Fragment, das Oestermann bestimmte, den Titel Persica, aus deren zweitem Buche es zitiert wird, für das Werk uber Alexander in Anspruch zu nehmen. Das besondere Verhältnis, das die Historiographen Alexanders zu dieser Stelle haben, wird eine eingehendere Behandlung rechtfertigen.

Beinah gleichlautend berichten Strabo XIV p. 672 und Athenaeus XII p. 530 b, nach Aristobulos, Athenaeus im Wortlaut ein klein wenig genauer: nicht weit ron Anchiale sei das Grabmal des Sardanapal gewesen, mit einem steinernen Bildnis, das mit den Fingern der Rechten ein Schnippchen zu

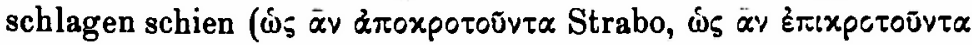
Athen.), und es habe darauf die Inschrift in assyrischen Buchstaben gestanden: 'Sardanapal, Sohn des Anakyndaraxes, baute Anchiale und Tarsos an einem Tage. Is, trinke und scherze, denn der Rest ist nicht soviel wert', nämlich wie ein Schnipp-

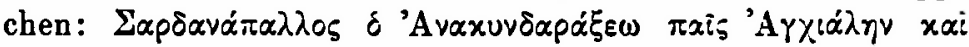

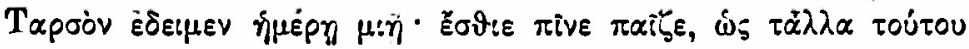

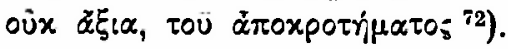

Etwas abweichend erzählt Arrian II 5, 2 ff., Sardanapal

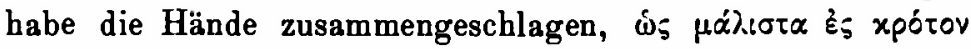
$\sigma \cup \mu \beta \dot{\alpha} \lambda \lambda \alpha \tau \tau \alpha$. Die Inschrift selbst gibt er folgendermaken

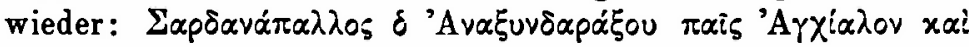

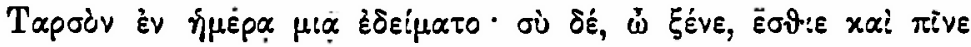

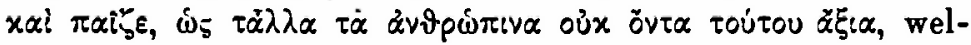

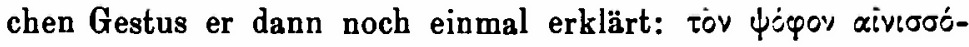

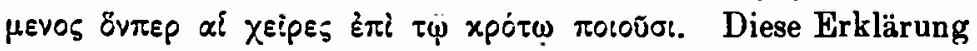
ist bei der beschriebenen Haltung der Hände weniger deutlich als die des Aristobulos. Das Beifallklatschen aber, woran man sonst denken würde, widerspricht dem unmifaverständlichen Sinn der Worte und würde keine Pointe ergeben.

Andererseits stimmt der Rahmen der Erzählung bei Arrian

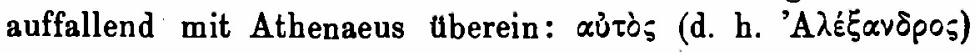

71) Pol. XII 18, 12.

72) вoเxє $\lambda \dot{s} \gamma \varepsilon เ v$ setzt Athenaeus hinzu. 


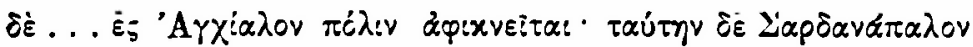

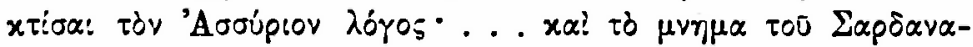

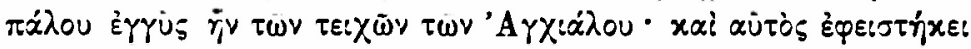

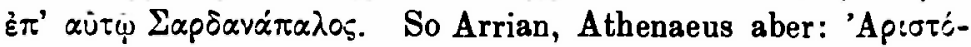

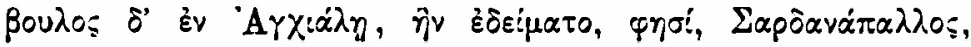

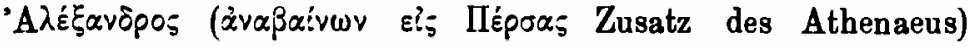

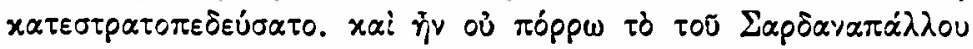

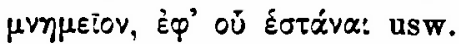

Hieraus muf man, wie mir scheint, schließen, daß A rrian zwei verschiedene Ueberlieferungen miteinander verschmolzen hat. Der zweite Teil der Inschrift stimmt nicht mit der Beschreibung, die von dem Bilde gegeben wird: $\Sigma \alpha \rho \delta \alpha v \alpha \dot{\pi} \alpha \lambda 0_{5}$

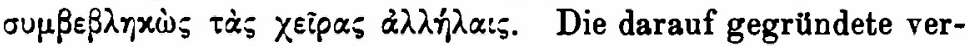
legene Erklärung aber, die gern zu demselben Resultat kommen möchte, wie die des Aristobul, ohne es zu vermögen, erweist sich zugleich durch den Ausdruck (vgl. xpótos und ėrt-

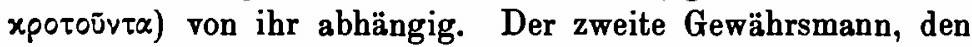
Arrian neben Aristobulos benutzt hat, kann nach der Angabe, die er selbst von seiner Arbeitsweise macht, nur Ptolemaeus gewesen sein.

Daß3 Ptolemaeus selbst Aristobul benutzt habe und Arrian ihm einfach gefolgt sei, wie Ed. Meyer meint ${ }^{73}$ ), scheint mir weniger wahrscheinlich. Wie viel Arrian dem Ptolemaeus verdankt, läßst sich freilich nicht mit Sicherheit erkennen. Mit Sicherheit darf man nur behaupten. daßj es zwei verschiedene Beschreibungen des Bildes gegeben habe, eine, nach der Sardanapal mit den Fingern der rechten Hand schnalzte, eine nach der er die Hände zusammengelegt hatte, und daß der ersteren Aristobulos folgte.

Noch ein anderer Geschichtsschreiber Alexanders, Amyntas, erwähnte nach A thenaeus XII p. $529 \mathrm{e}$ in dem dritten Buche seiner $\Sigma \tau \alpha \vartheta \mu o l$ ein Denkmal Sardanapals, aber nicht das in Anchiale, sondern in Ninive. Es sei von Cyrus zerstört worden und auf einer steinernen Stele habe eine Inschrift gestanden, die Choirilos metrisch übersetzt habe.

In dem vierten Buche seiner Geschichte Alexanders sprach Kleitarchos von Sardanapal, wie nach dem Zusammenhange

79) Forschungen z, a, Gesch. I 208. 
bei Athenaeus, dem wir auch diese Notiz verdanken (p. 530a), anzunehmen ist, ebenfalls in Anknüpfung an eines der beiden Denkmäler.

Von diesen beiden Denkmälern handelte nun nach einer identischen Notiz bei Suidas, Photius und in einigen aus einem Lexikon interpolierten Paroemiographenhandschriften Kallisthenes in dem zweiten Buche der Persica. Er unterschied zwei Sardanapale, einen tüchtigen und tatkräftigen und einen weichlichen, aus welchen Gründen, wird aus der Notiz nicht

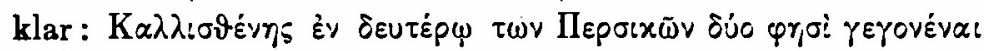

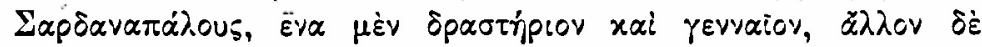

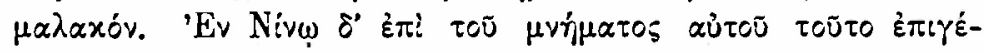

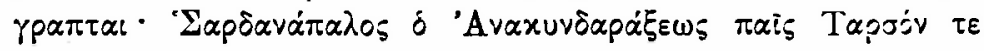

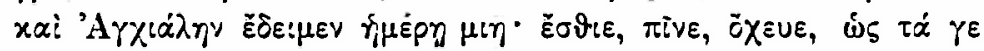

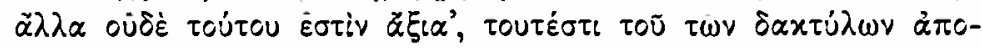

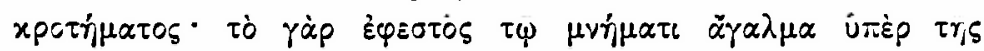

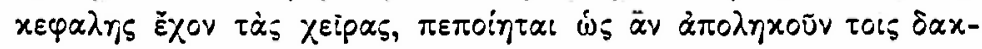

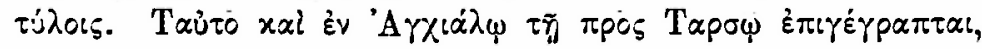

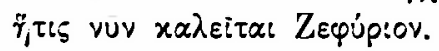

Zwei Sardanapale hatte nach dem Scholion zu Aristophanes $\nabla_{00} 1021$ auch Hellanikos unterschieden, woraus C. Müller geschlossen hat, dafs in der Notiz des Suidas der Name des Kallisthenes fälschlich für den des Hellanikos gesetzt sei.

In dem Scholion sind drei verschiedene Angaben zu unterscheiden. Die erste und dritte, untereinander nah verwandt, sind anonym, die mittlere, die hier in Betracht kommt, geht auf den Namen des Apollodor. Diese kommt nun allerdings dem Wortlaut der Notiz des Suidas, bis auf den Namen Hellanikos, so nahe, dak man an einem gemeinschaftlichen Ursprung bei-

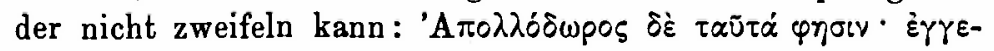

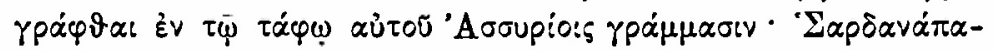

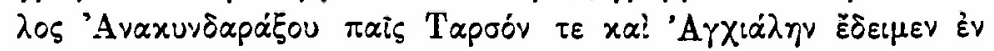

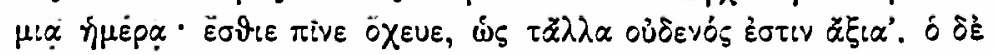

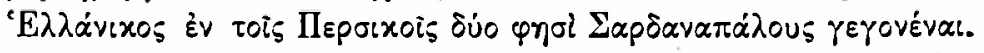

Das Scholion ist, wie man sieht, stark gekürzt, und der Schluß der Inschrift ist wie bei Plutarch so verändert, daß eine Erklärung nicht mehr nötig ist, aber die Gleichheit des 


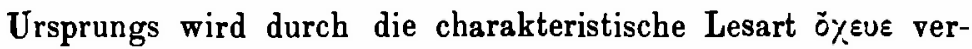

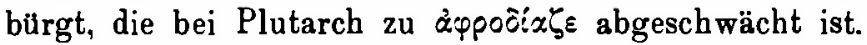

Die Bemerkung uber Hellanikos scheint mit dem Vorhergehenden nichts zu tun zu haben, so daß̧ Müller sich verleiten lief, das Folgende damit zu verbinden. Allein es wird sich zeigen, daß die Erwähnung des Hellanikos keineswegs zufällig oder willkürlich ist.

Die auch noch bei Aristobulos erhaltenen Ionismen in der Notiz bei Suidas haben, wie es scheint, zum ersten Male Niese ${ }^{74}$ ) zum Nachdenken angeregt. Er schlok aus ihnen, dak Kallisthenes einen älteren Schriftsteller ausgeschrieben habe und vermutete unter diesem keinen andern als - Hellanikos.

Diese Vermutung wird durch das Scholion zu den Vögeln in ein überaus günstiges Licht gestellt. Es fragt sich nur, ob nicht doch der Name des Kallisthenes bei Suidas auf einem Irrtum beruht. Aber dieser Irrtum wärde eine Erklärung fordern, die sehr schwer zu geben wäre, da die bloßen Namen jedenfalls keinen Grund zur Verwechselung boten. Da zudem der Scholiast stark gekürzt hat, so bleibt es wahrscheinlicher, $\mathrm{da}_{\mathfrak{B}}$ in der Tat Kallisthenes aus Hellanikos geschöpft hat. Daran, dak dieser als die Urquelle anzusehen ist, kann kein Zweifel bestehen, denn durch die Ionismen ist sein Name unendlich viel besser bezeugt als der des Kallisthenes.

Der Text des Aristobulos erweist sich durch die Lesart $\pi x i \zeta_{\varepsilon}$ als sekundär. Auch Ptolemaeus, wenn er bei Arrian als Gewährsmann für den von ihm gebotenen Text und seine Erklärung anzunehmen ist, befolgte diese Lesart, kannte aber auch die andere, die er aus Gründen der Decenz vermied, denn Arrian sagte, $\mathrm{da}_{\mathfrak{\xi}}$ im Original für $\pi x i \zeta \zeta_{\varepsilon}$ ein leichtfertigerer Ausdruck stünde.

Hier lernen wir eine dritte Beschreibung des Bildes kennen: Sardanapal hält beide Hände uber dem Kopf, aber nicht zusammengelegt, sondern die Finger, beider Hände wie es scheint, machen denselben Gestus wie nach der Beschreibung Aristobuls und es wird davon auch dieselbe Erklärung gegeben.

7) De Sardanapalli epitaphio Ind. lect: Marburgi 1880 p. IX. 
Dieselbe Fassung war auch Plutarch bekannt, der sie in der Schrift De Alexandri fortuna aut virtute p. $336 \mathrm{C}$ erwähnt. Er scheint aber eine ausfuhrlichere Beschreibung davon gelesen zu haben, denn er sagt, daß Sardanapal tanzend dargestellt sei, wozu die Haltung, der Hände gut pact. Bemerkenswert ist, dak er dabei ebenso, wie es bei Suidas und auch bei Aristobulos geschieht, unmittelbar von dem Bilde als dem

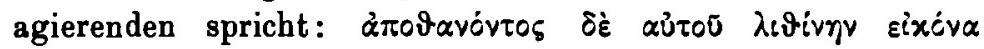

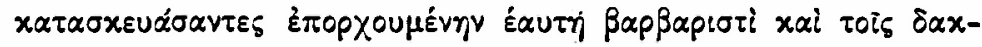

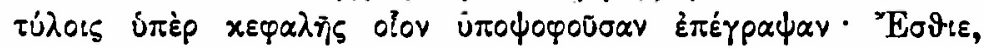

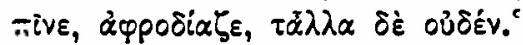

Auch Klearchos von Soli beschrieb das Bild bei Athen. p. $529 \mathrm{c}$ als das eines Tanzenden, wie aus der Wendung rot-

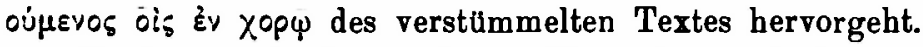

Es fragt sich aber noch, ob Hellanikos auch das Denkmal in Anchiale gekannt hat oder aber ob davon erst Kallisthenes gesprochen hat. Aus dem Schweigen des Apollodor in dem Scholion zu den Vö. darf man keine Schlüsse ziehen, da das Scholion, wie wir gesehen, stark verkürzt ist.

Ueberlegen wir den Inbalt der von Hellanikos mitgeteilten und erklärten Inschrift, so ist klar, daß die beiden Sätze so nicht zu einander passen. Es fehlt ein vermittelnder Gedanke, der die bedonistische Moral begründet, etwa so: , alle Bemühungen um Rubm und Ehre sind eitel, denn der Tod macht allem ein Ende". Diesen Gedanken fügte Klearch an den ersten Satz an, liek dafür aber die Schlukfolgerung weg und gab die Inschrift demnach in folgender Form:

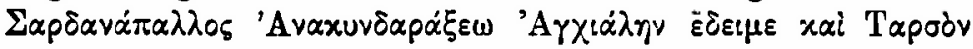

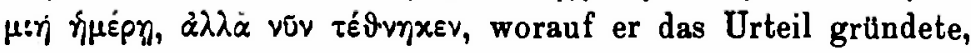
Sardanapal sei keineswegs ein tatenloser Mann gewesen, ohne jedoch von einem $\mathrm{zweiten} z u$ sprechen ${ }^{75}$ ). Auch Klearch erweist sich durch die Ionismen als mittelbar oder unmittelbar von Hellanikos abhängig, und es ist kaum anders denkbar, als daß Hellanikos die Unterscheidung zweier Sardanapale ähnlich begründet hatte. Aber wie kam er dann dazu zu glauben, daß auf der Grabschrift des Tatkräftigen der Grund-

75) Athen. XII p. $529 \mathrm{e}$. 
satz des Weichlings mit dem Zeugnis seiner Unternehmungslust verbunden gewesen sei?

Wie immer das nun auch zusammenhängen mag, so kann man nicht $\mathbf{z w e i f e l n , ~ d a \xi ~ d i e ~ v o n ~ H e l l a n i k o s ~ b e k a n n t ~ g e m a c h t e ~}$ Inschrift irgendwie auf Kompromiß beruht. Die erste Hälfte besteht sehr gut für sich, nur daf es dann keine Grabinschrift ist und sie auch nichts mit Ninive zu tun hat, sondern nach Anchiale oder Tarsos gehört. Sie klingt, so gefaft, auch gar nicht unwahrscheinlich und scheint jedenfalls einen historischen Kern zu enthalten. Nun erzählte Berossos nach Eusebius ${ }^{76}$ ), dak der König Sanherib in Cilicien zum Andenken an seinen Sieg über die Ionier sein Bildnis mit einer Inschrift in chaldäischen Buchstaben habe errichten lassen. So findet die behauptete Existenz des Denkmals eines assyrischen Königs in Anchiale durch eine unabhängige Ueberlieferung eine $\mathrm{Be}-$ stätigung.

Nach Amyntas war in der Grabschrift des Sardanapal in Ninive keine Rede von Städtegründungen oder anderen Taten, sondern nur von dem Wohlleben, das der König in dem Bewuf́tsein der Kürze des Lebens geführt hatte. Es ist also genau derselbe Inhalt, der in dem zweiten Satze der Inschrift des Hellanikos als allgemeine Lebensregel erscheint. Wäre als der angebliche Uebersetzer nicht Choerilus genannt, so würde man ohne weiteres annehmen, daf in der Inschrift des Hellanikos die Inschrift von Anchiale mit dieser fiktiven Grabschrift kombiniert sei, nun aber hat es den Anschein, als wenn umgekehrt diese fiktive Grabschrift aus der kürzeren Form des Hellanikos umgebildet sei. Denn niemand zweifelt nach dem Vorgang von Naeke ${ }^{77}$ ), daß der genannte Choerilus der verrufene Dichter Alexanders des G. sei.

Allein diese Meinung steht nicht auf sehr festen Füßen. Das einzige Argument, das, soviel ich sehe, dafür angeführt wird, ist, dak der Commentator Cruquianus und Porphyrio zu Horaz A. P. 357 bemerken, dieser Choerilus habe nur sieben lobenswerte Verse gemacht. Wenn damit die Grabschrift ge-

70) Cbron. ed. Schoene p. 27.

17) Choerili Samii quae supersunt 1817 p. 196 sqq. 
meint ist, so muls sie dem Gewährsmann der beiden in der Form bekannt gewesen sein, in der sie bei Athenaeus VIII 336 a zitiert wird:

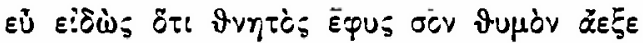

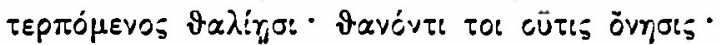

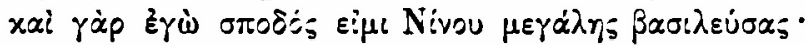

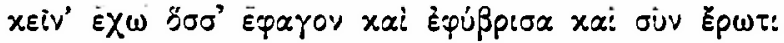

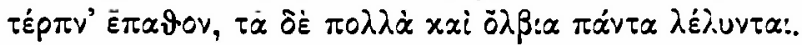

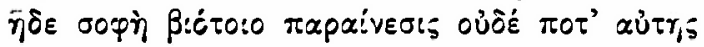

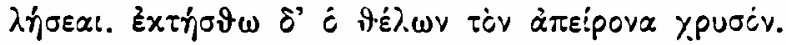

Mit diesem Zitat aber hat es eine eigene Bewandtnis. Es hat in den beiden häufig auch für sich angeführten Versen 4 und 5 eine Reihe von Sonderlesarten, nämlich $x \in \dot{s} y^{\prime} \ddot{\varepsilon}_{\%} \omega$ st.

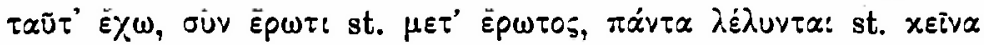
$\lambda \dot{\varepsilon} \lambda \varepsilon \iota \pi \tau \alpha \iota$, die beiden letzten Verse aber sind anderswo nicht überliefert.

Nun hat Chrysipp, wie wir weiter bei Athenaeus p. 337 a lesen, die Verse im Geiste der stoischen Philosophie umgedichtet. Hierbei hat er aber nicht den ihm von Athenaeus p. 336 a zugeschriebenen Text zugrunde gelegt, sondern die Vulgata, nur V. 5 hat er $\pi \dot{v} v \tau \alpha$ st. xeiv $\alpha$, aber V. 6 und 7 fehlen. Die beiden Verse sind also nicht ganz sicher beglaubigt, obwohl der Schluk im Sinne des Apres nous le deluge zu dem Cynismus des Ganzen wohl pakit.

Aber wenn auch die beiden Verse echt sind und der Gewährsmann des Prophyrio an eben diese sieben Verse gedacht hat, was ist damit gewonnen? Kann das Zeugnis eines unbekannten römischen Grammatikers irgend welche Autorität beanspruchen und lag es nicht für jeden Horazerklärer nahe, was er zufällig ron Choerilus gehört oder gelesen hatte, auf den von Horaz gebrandmarkten Hofdichter Alexanders (Ep. II 1, 232 ff.) zu beziehen?

Der jüngere Choerilus kann aber die Grabschrift gar nicht verfaßt haben, weil die beiden häufig für sich angeführten Verse nach dem Zeugnisse Ciceros De fin. II 106 und Tusc. V 101 schon dem Aristoteles bekannt waren, und zwar, wie Ciceros Uebersetzung beweist, in der Lesart der Vulgata : 
Haec habeo quae edi quaeque exsaturata libido hausit, at illa iacent multa et praeclara relicta.

Naeke hat sich dem Gewicht dieser Tatsache durch die geradezu verzweifelte Annahme zu entziehen gesucht, der jüngere Choerilus habe diese Verse von einem älteren Dichter ubernommen. Aber Aristoteles hat sie aus Ktesias und Ktesias hatte sie mit den drei vorhergehenden zusammen zitiert.

Aristoteles' Abhängigkeit von Ktesias verrät die Ueber-

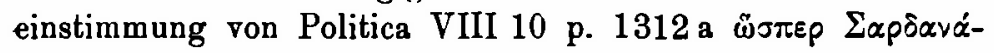

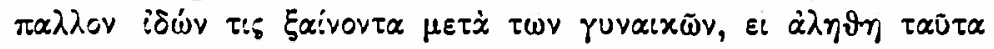

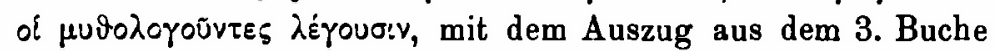

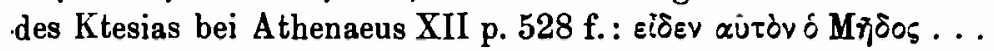

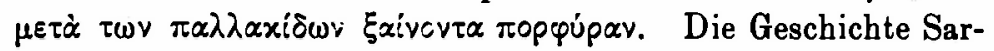
danapals erzählt auch Diodor II 24-27 nach Ktesias, ohne ihn zu nennen, wie die Vergleichung mit Athenaeus zeigt. Aber auch die allgemeine Charakteristik des Königs c. 23 ist Ktesias entnommen. Bei Athenaeus ist diese an dem eben genannten Orte mit der Erzählung verwoben, bei Diodor fehlt sie an der entsprechenden Stelle und wird für sich der Erzählung vorausgeschickt. Aber die Schilderung ist bei beiden dieselbe:

Diod.

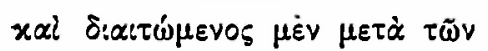
$\pi \alpha \lambda \lambda \alpha x i \delta \omega \nu, \pi \circ \rho \varphi \varphi ́ p \alpha \nu \delta \dot{\varepsilon} x \alpha i$

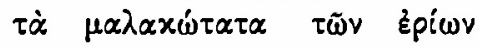

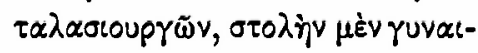

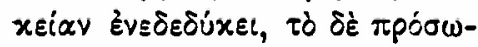

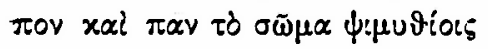

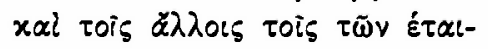

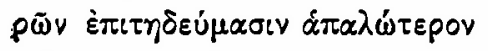

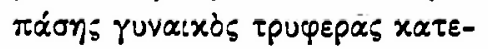

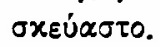

Athen.

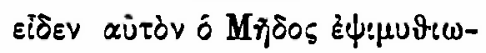

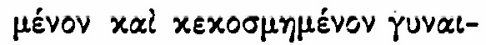

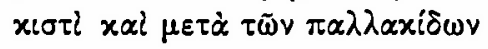

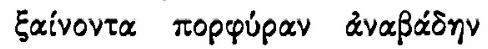

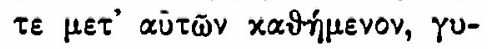

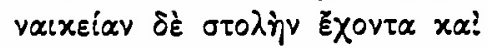

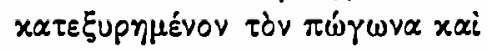

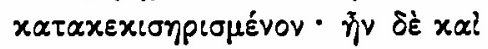

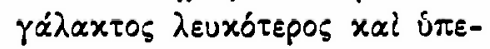

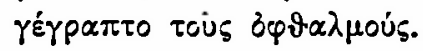

Diodor erweitert dann das Bild noch durch andere bezeichnende Züge, die Athenaeus in seinem Zusammenhange nicht anbringen konnte, und schlieft die Schilderung mit der Grabschrift V. $1-5$ ab.

Dás die Verse nicht von vornherein als angebliche Uebersetzung einer Grabschrift fur sich bestanden, sondern einem Philologus LXXIV (N. F. XXVIII), 1. 
größeren erzählenden Zusammenhange angehört haben, beweist die stichische Form. Ganz besonders sind die von Näke als die ursprangliche Grabschrift angenommenen beiden Verse in dieser Form als solche undenkbar.

Sicherlich nicht ohne Zusammenhang mit diesen Versen ist die von dem Kallimacheer Istros bei Athenaeus VIII 345 d erzählte Anekdote von dem ältern Choerilus, daß er die vier Minen, die er täglich von Archelaos bekommen habe, für seine Küche verbraucht habe.

Im Unterschied von der Grabschrift des Hellanikos sind die Verse des Choerilus nicht als Erläuterung einer bildlichen Darstellung gedacht, sondern erklären sich aus sich selbstSie können nicht auf den letzten Assyrerkönig erfunden sein, denn der verlor sein Reich und seine Hauptstadt wurde von Grund aus zerstört. Darum sagte Ktesias vorsichtig, er habe die Inschrift auf sich selbst gemacht und befohlen, sie nach seinem Tode auf sein Grab zu setzen ${ }^{\text {i8}}$ ). Aber auch die Erzählung seines Endes straft die Inschrift Lügen und namentlich der von Chrysipp überlieferte Schluk, es sei ihm gleichgültig, wer nach seinem Tode in den Besitz seiner unendlichen Reichtümer komme, steht im schneidenden Widerspruch mit dem Bilde des Königs, der all sein Gold und Silber und seine kostbaren Gewänder auf dem Scheiterhaufen verbrennt, den er selbst mit seinem ganzen Harem besteigt, damit seine Schätze nicht dem Feinde anheimfallen. Wenn daher Diodor die Charakteristik des Königs mit dieser Erzählung sehr ungeschickt durch die Bemerkung verbindet, er habe nicht nur selbst sein Leben schimpflich geendet, sondern auch das alte Assyrerreich vollständig zerstört, so heißst es bei Athenaeus richtiger und ohne Zweifel mehr in Uebereinstimmung mit Ktesias, Sardanapal sei trotz seiner auferordentlichen Ausschweifungen tapfer gestorben ${ }^{79}$ ). Duris konnte über diesen Gegensatz so wenig hinwegkommen, daß er kurz entschlossen die Erzählung von den Siegen Sardanapals über die Empörer und seinem selbstgewählten Tode strich und statt dessen er-

93) Bei Diodor II 23, 3.

19) Athen. XII $529 \mathrm{~d}$. 
zählte, der Meder Arbakes habe ihn, empört über seinen weibischen Anblick, niedergestochen ${ }^{80}$ ).

Offenbar setzen aber die Verse des Choerilus auch voraus, daß der König ebenso vergnügt gestorben sei, wie er lustig gelebt habe. Man kann auch zweifeln, ob die Verse ron Choerilus selbst gerade auf Sardanapal gemunzt waren, wenn aber, so galt er ihm wohl als Typus der assyrischen Könige uberhaupt, wie ja nach Ktesias die Charakteristik, die er von dem letzten Könige gab, auf alle seine Vorgänger außer dem Grüder selbst pakte, von Ninjas, dem Sohne des Ninus und der Semiramis an ${ }^{81}$ ). Als Typus ist Sardanapal offenbar auch von Aristophanes in den Vögeln gefábt.

Ueber das chronologische Verhältnis des Hellanikos und des älteren Choerilus zu einander sind wir nicht hinreichend unterrichtet, insbesondere kennen wir weder die Abfassungszeit der Persica des einen noch des andern. Da aber Hellanikos in der von ihm angefuhrten Inschrift zwei verschiedene Vorstellungen vereinigte, von denen die eine in den Versen des Choerilus nicht berücksichtigt ist, die andere aber einen durchaus selbständigen Eindruck macht, so mú die Abhängigkeit auf Seiten des Choerilus liegen.

Der Beschreibung des angeblichen Grabdenkmals liegt ohne Zweifel irgend eine bildliche Vorstellung zugrunde. Diese ist aber nicht mit der Abbildung identisch gewesen, die Ed. Meyer in seinem Aufsatz S. 205 aus Perrot und Chipiez wiederholt hat. Denn Hellanikos sprach ja von dem Bilde eines Mannes in tanzender Haltung, der die beiden Hände über dem Kopf hielt. Die Abbildung bei Perrot und Chipiez läbt sich dagegen mit der Beschreibung Aristobuls sehr wohl vereinigen, denn der König hält die Finger der in der Höhe des Mundes seitwärts gewendeten rechten Hand so, wie Aristobulos es beschrieb. Aber darum ist es doch äuferst fraglich, ob er dabei eine eigene Anschauung gehabt hat, denn er sagt nicht, wie hoch der König die Hand hielt. Es ist sehr wohl möglich, tür mich gewí, daf Aristobulos nichts anderes vor sich hatte als die Beschreibung, die von Hellanikos gegeben war, die er abkürzte, wobei

80) Ders. 529 a.

B) Diod. II 21 g. E. 
er statt des Plurals den Singular setzte. Nicht zu übersehen ist, daG in der Erklärung Aristobuls für die Bewegung der Finger

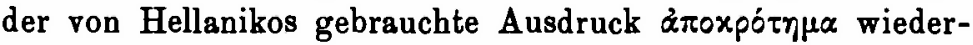
kehrt.

Ebensowenig läkt sich behaupten, daß der mutmaßich auf Ptolemaeus zurückgeführten Beschreibung bei Arrian ein Bild wie das bei Ed. Meyer S. 208 zugrunde liegt. Denn unmöglich kann bei dieser Beschreibung, wie schon gesagt, an Beifallsklatschen gedacht sein, weil dann die Erklärung zu der Inschrift nicht paft, sondern der Ausdruck xpóto;

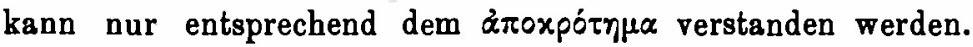
Auch hier wird lediglich eine Nachlässigkeit in der Wiederholung der alten Beschreibung vorliegen. Der Plural Hände ist geblieben, dafür ist aber von den Fingern keine Rede mehr, wohl aber ist für die Ausübung ihrer Tätigkeit dasselbe Verbum gebraucht, das Aristobulos angewendet hatte,

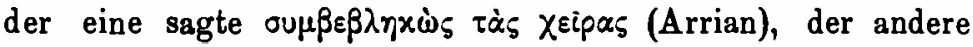

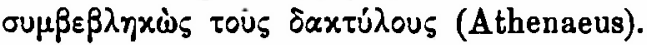

Uebrigens ist die Beschreibung des Denkmals bei Arrian, die im ganzen zwar als eine Digression erscheint, doch insofern mit den Ereignissen des Feldzugs rerknüpft, als von Assyrern die Rede ist, die bei der Erklärung der Inschrift Dienste leisten. Es ist dabei augenscheinlich an die Bewohner von Anchiale gedacht. Aber diese Assyrer sind eine sehr schlechte Erfindung, da nicht bedacht ist, dak Anchiale in Cilicien liegt und abgesehen davon ja auch die Syrer, denen die Assyrer hier gleichgesetzt sind, diese Inschrift gar nicht hätten lesen können. Sie wissen auch, dak das Original metrisch abgefaßst ist. Es liegt also eine Vermengung mit der angeblich von Choerilus übersetzten Grabschrift ron Ninive zugrunde. Hat Arrian diese Fiktion gemacht oder hat er sie in seiner Quelle gefunden? Assyrien ist auch im weiteren Verlauf der Erzählung gleich Syrien gesetzt (II 6, 1.3), das stammt also aus seiner Quelle und so wird man auch den Versuch, die Bekanntschaft mit dem Denkmal als ein wirkliches Erlebnis erscheinen zu lassen, während sie tatsächlich in der Literatur wurzelte, darauf zurückführen müssen.

Wenn Hellanikos ron einem Grabdenkmal Sardanapals in 
Anchiale und von einem andern in Ninive gehört hatte, so sollte man glauben, daß damit für ihn die Unterscheidung zweier Sardanapale gegeben war. Aber das kann es nicht gewesen sein, was ihn bestimmte, denn dann hätte er ja nicht die beiden Inschriften miteinander vereinigt. Nach Abydenus haftete der Name Sardanapal nicht an dem letzten, sondern dem vorletzten Könige der Assyrer. Ob darin ältere Ueberlieferung steckt?

Ich sehe keine Möglichkeit, hier zu irgend 'einer Klarheit zu kommen. Ebensowenig in einem zweiten Punkte.

Mochte nun Hellanikos den Sardanapal auf dem Denkmal in Anchiale mit dem Sardanapal auf dem Denkmal in Ninive für identisch halten oder nicht, so konnte er doch in dem einen Falle so wenig wie in dem andern annehmen, daßs beide Denkmäler dasselbe Bild mit derselben Inschrift hatten; ebensowenig in dem andern Kallisthenes, von dem es die Notiz bei Suidas behauptet, noch irgend ein halbwegs verständiger Schriftsteller. Aristobulos und Ptolemaeus sprachen zwar von dem Denkmal in Apchiale als einem Grabdenkmal, aber sie sprachen nicht von dem Denkmal in Ninive, andererseits Amyntas wohl von diesem, aber nicht von jenem.

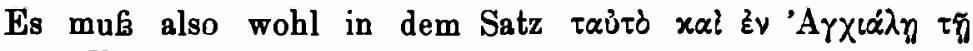

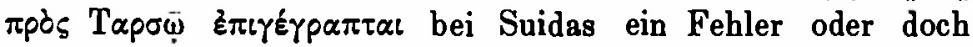
mindestens eine Ungenauigkeit stecken. Andererseits darf man nicht übersehen, dak das, was Kallisthenes nach Hellanikos in erster Linie von dem Denkmal in Ninive ausgesagt hatte, von Aristobulos und Ptolemaeus in der Hauptsache genau in derselben Weise von dem in Anchiale ausgesagt wurde.

Da Kallisthenes den Hellanikos wörtlich zitiert hat, so ist es an und für sich unmöglich zu sagen, ob Aristobulos und Ptolemaeus den Kallisthenes oder den Hellanikos benutzt haben. Das aber steht außer Zweifel, dak Kallisthenes nicht aus einem von diesen beiden geschöpft hat. Damit ist aber zum mindesten die Wahrscheinlichkeit gegeben, dak diese beiden von dem jüngeren Schriftsteller abhängen. Es ist begreiflich, daß dieser Tatbestand zu dem Schluß gefuhrt hat, das Fragment des Kallisthenes gehöre zu seiner Schrift über Alexander. Wäre das der Fall, so hätte man den Beweis in 
Händen, daß̧ diese Schrift nicht während der Feldzilge Alexanders, sondern in der Stille einer Gelehrtenstube verfafit war, da kaum eine zweite Stelle so deutlich verraten konnte, wie sehr dieser Verfasser mit Büchern arbeitete und wie wenig er aus lebendiger Anschauung und persönlichen Erlebnissen schrieb.

Angenommen aber, wir wubten sonst nichts von einer Schrift des Kallisthenes uber Alexander, so würde schwerlich irgend jemand auf Grund dieser Stelle eine solche Schrift postulieren; jedermann würde vielmehr annehmen, daß̧ die Persica des Kallisthenes, aus denen die Stelle zitiert wird, ein Werk in der Art der gleichbetitelten Werke des Hellanikos und Ktesias gewesen sei.

Eine solche Annahme findet die beste Unterstützung in den Fragmenten des Kallisthenes, denn mehrere von denen, die Geier dem Geschichtswerk über Alexander zugewiesen hat, lassen sich ebenso zwanglos in eine persische Geschichte einfügen, wie sie einer Geschichte Alexanders widerstreben.

So fr. XVIII bei Geier $==$ Strabo XI p. 531: oũtos $\mu \grave{\varepsilon} v$

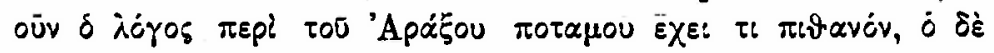

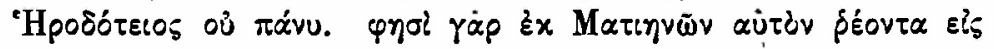

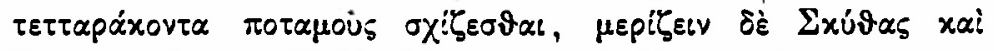

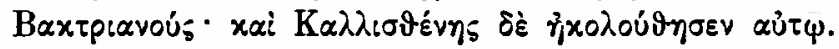

Es ist möglich, dak in dem pseudo-kallisthenischen Werke die Jagd auf Bessos und Alexanders Marsch an den Iaxartes noch geschildert waren. Die Makedonen nannten ihn den Tanaïs, aber die Historiographen, insbesondere Aristobulos, waren sich wohl bewufit, daks er von dem Tanaïs Herodots verschieden war ${ }^{82}$ ). Ueber den Araxes scheinen sie nicht ins Klare gekommen zu sein. Er wird bei Arrian unter den Flüssen genannt, die in das kaspische Meer münden, neben dem Oxus und laxartes, aber was von diesen als Tatsache ausgesagt wird, wird von dem Araxes als Gerulcht bezeichnet ${ }^{83}$ ). Den Araxes hatte Alexander auf seinen Zügen eben nicht angetroffen. Es war keine Veranlassung bei der Schilderung seiner Züge durch Baktrien und Sogdiana von ihm zu sprechen, es sei denn für einen, der ihn mit dem Iaxartes ver-
82) Arrian III 30, 7.
83) VII $16,3$. 
wechselte, und es würde ein ganz besonders schlechtes Zeugnis für einen die Ereignisse unmittelbar verfolgenden Historiker sein, wenn er statt die neugewonnenen Erkenntnisse in sich aufzunehmen, bei den verworrenen Vorstellungen Herodots verharrte.

Alles erklärt sich auf das einfachste, wenn wir annehmen, daß Kallisthenes den Araxes erwähnte, als er in der persischen Geschichte den Zug des Cyrus gegen die Massageten erzählte. Niemand wird ihm einen Vorwurf machen, wenn er dabei dem Vorgange Herodots (I 202) folgte.

Die Einnahme von Sardes durch die Makedonen, meint Geier, habe Kallisthenes Gelegenheit geboten, von den früheren Eroberungen der Stadt zu reden. Daher weist er dem Geschichtswerk aber Alexander fr. III = Strabo XIII p. $627 \mathrm{zu}$

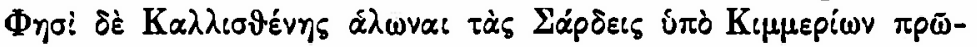

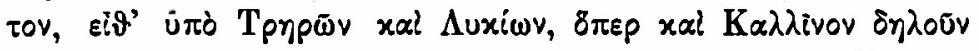

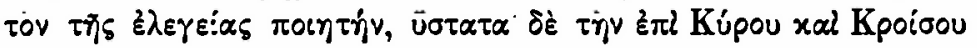

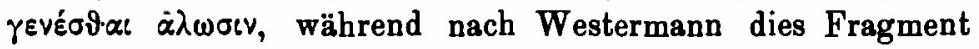
dem ron dem Scholiasten des Apollonius Rhodius I 1037 bezeugten Periplus des Kallisthenes angehört. Aber wie hätte Kallisthenes an dem einen oder anderen Orte so reden können, da ja doch Sardes zum vierten Male in dem ionischen Aufstande eingenommen wurde? Handelte dagegen Kallisthenes in der persischen Geschichte von der Einnahme der Stadt durch Kyros und war dies die Quelle des Strabo, so versteht man, wie seine wunderliche Notiz zustande gekommen ist. Kallisthenes wird auch dort nicht gesagt haben, dak dies die letzte Eroberung von Sardes gewesen sei, aber er wird die beiden vorhergehenden erwähnt haben, und er brauchte natürlich nicht auf die spätere einzugehen.

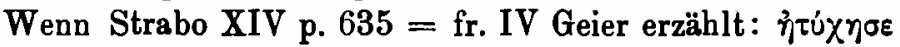

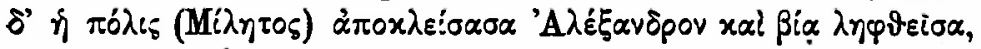

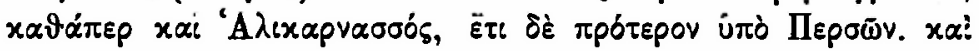

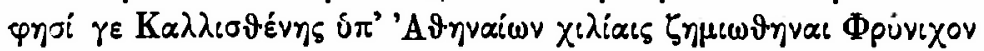

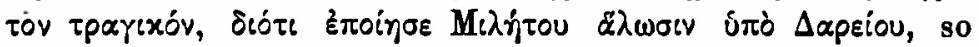
wübte ich nicht, wie man aus dieser Stelle selbst beweisen wollte, dak Strabo auch die Kenntnis von der Einnahme Milets durch Alexander dem Kallisthenes verdanke. Wiederum aber 
würde die dem Herodot nacherzählte Anekdote in einer persischen Geschichte ihren guten Platz gehabt haben.

Eine ganze Reihe von Fragmenten, die Westermann dem Periplus zugewiesen hat, nimmt Geier für das Werk über Alexander in Anspruch. Ich sehe keinen Grund, das Zeugnis des Scholiasten des Apollonius R!.odius zu bezweifeln ${ }^{84}$ ), wenn man auch im einzelnen zweifeln kann, welche von den nur mit dem Namen des Autors benannten Fragmenten dieser Schrift angehören. Führt man aber mit Geier, diese Fragmente auf die Schrift über Alexander zurück, so ergibt sich die Vorstellung von einem mit gelehrtem, von der Hauptsache weit abliegendem Detail derartig überladenen Werke, dak schon damit seine Unechtheit genügend bewiesen wäre. Denn Werke solcher Art entstehen nicht während der Ereignisse auf ihrem eigenen Schauplatz.

Wir haben aber alle Ursache uns ein völlig anderes Bild von der Schrift zu machen. Dazu berechtigen uns einmal die allein sichern Fragmente davon und dazu gehören nicht mehr als Fr. 21-26 bei Westermann ${ }^{85}$ ), mit Ausnahme von 23a, sodann die oben besprochenen Aeukerungen des Timaeus Polybius und Arrian. Es war eine Schilderung der Ereignisse, durch die Alexanders Göttlichkeit erwiesen werden sollte. Das Werk wird auch durch eine Bemerkung charakterisiert, die, wie Westermann gesehen bat, an seinem Anfang gestanden haben muß. Wir haben durch den Mechaniker Athenaeus

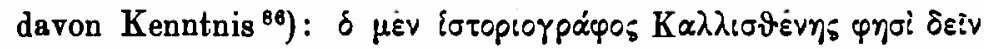

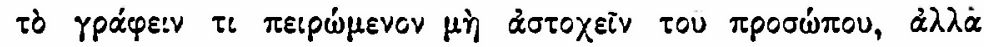

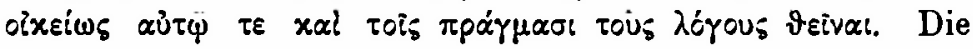
Angabe ist schwerlich ganz genau und vollständig. Ich vermute, dak Plutarch in seiner Einleitung des Lebens Alexanders

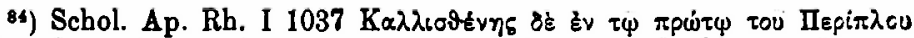

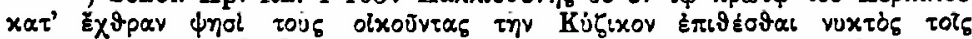

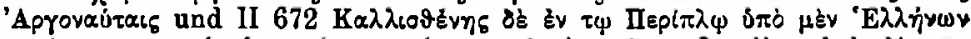

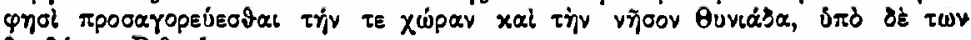

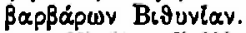

85) De Callisthene Olynthio II 2 Rerum Persicarum fragmenta Leipziger Universitätsprogr. 1842. Westermann zählt noch fr. 20, das den Sardanapal betrifft, dazu.

8o) Westermann fr. 21. V̈gl. über ihn Rochas d'Aiglun in Melanges Graux p. 782. 
der Gedanke rorgeschwebt hat, wenn er ihn auch in anderer

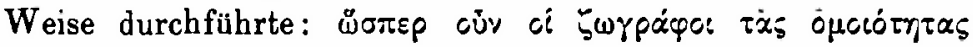

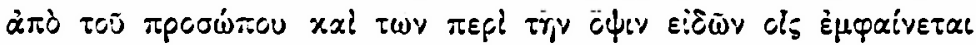

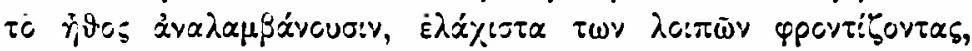

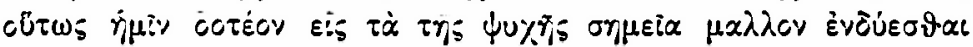

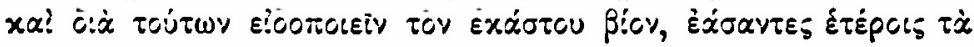

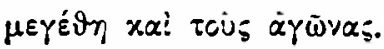

Berlin-Dahlem.

P. Corssen. 